\title{
Development and Characterization of Green Automotive Brakepads from Waste Shells of Giant African Snail (Achatina Achatina L.)
}

Chinwuba Victor Ossia ( $\square$ chinwuba.ossia@uniport.edu.ng )

University of Port Harcourt

\section{A. Big-Alabo}

University of Port Harcourt

\section{Research Article}

Keywords: Green brake pads, giant African snail shells, Hall-Petch equation, grain size, power law model

Posted Date: February 24th, 2021

DOl: https://doi.org/10.21203/rs.3.rs-227614/v1

License: (c) (1) This work is licensed under a Creative Commons Attribution 4.0 International License.

Read Full License

Version of Record: A version of this preprint was published at The International Journal of Advanced Manufacturing Technology on April 18th, 2021. See the published version at https://doi.org/10.1007/s00170-021-07085-4. 


\title{
Development and Characterization of Green Automotive Brakepads from Waste Shells of Giant African Snail (Achatina achatina L.)
}

\author{
Chinwuba Victor Ossia.* and Akuro Big-Alabo \\ Applied Mechanics \& Design Group, \\ Department of Mechanical Engineering, \\ University of Port Harcourt, \\ Port Harcourt, Nigeria \\ *Correspondence: chinwuba.ossia@uniport.edu.ng
}

\begin{abstract}
In this study, waste shells of African giant snail (Achatina achatina L.) were explored as candidates for asbestos-free non-carcinogenic brakepads. The results obtained showed that the density, brinell hardness and compressive strength of the snail shell (SS) brake pads were superior to the commercial sample used for comparison. These properties were found to decrease with increase in particle size, following a negative index power law model after the order of the Hall-Petch equation. However, the liquid absorption characteristics increased with increase in particle size and its model followed a positive index power law due to the pores in the matrix. On the other hand, the thermal conductivity showed no significant change with variation in particle size. The SS-based brake pad exhibited better frictional grip at the rubbing interfaces compared to the commercial brake pad sample. From the frictional results obtained, the commercial brake pad can be rated as Edge-Code-D whereas the frictional rating for the SS-based brake pad with different particle sizes are Edge-Code-E $(500 \mu \mathrm{m}$ and $250 \mu \mathrm{m})$, Edge-Code-F $(375 \mu \mathrm{m})$, Edge-Code-G $(125 \mu \mathrm{m})$ and Edge-Code-H $(90 \mu \mathrm{m})$. The wear rates and wear areas of the developed SS-based brake pads were inferior to the commercial sample but can be improved by impregnating the matrix with more iron fillings to enhance the poor thermal conductivity and hence wear characteristics.
\end{abstract}

Keywords: Green brake pads, giant African snail shells, Hall-Petch equation, grain size, power law model

\section{Introduction}

The phasing out of asbestos-based materials for engineering applications due to their carcinogenic impact on human and animal health has prompted researches for "greener" alternatives. In tribological parlance, engineering materials that have negligible negative impacts on human and animal health, as well as, the environment are considered to be "green" materials, and hence the need to explore biodegradable materials. Locally available biodegradable materials such as, Rice husk and rice straw [1], palm kernel shells [2], coconut shells [3], periwinkle shells [4], [5] and saw-dust [6], have been explored with varying performance levels.

Mutuk and Gurbuz [7] investigated pure titanium samples of particle sizes $\leq 30 \mu \mathrm{m}, \leq 43 \mu \mathrm{m}$, and $\leq 150 \mu \mathrm{m}$ sintered at $1100^{\circ} \mathrm{C}$ for $120 \mathrm{~min}$ with a view to ascertain the role of particle size on the density, hardness, wear resistance and microstructural properties. In the study, the sample with lowest particle size $\leq 30 \mu \mathrm{m}$ showed the best mechanical properties. Their wear rate and SEM results indicated that the superior mechanical properties was attributable to good bonding and strong neck formation between the particles with smallest size. These results were corroborated by Ossia et al. [3] showing that particulate grain size affected the physico-mechanical properties of organic brake pads. 
In the search for green biodegradable alternatives to the carcinogenic asbestos-based commercial brake pads, waste African giant snail (Achatina achatina L.) shells are yet to be explored. Besides the opportunity to mop-up this waste organic material, its conversion to biodegradable brake pad composites will offer good economic and environmental competitiveness. It is this potential that the present study seeks to explore.

\section{Materials and Methods}

\subsection{Materials}

The base material for the green brake pad is the waste African giant snail shell, which were obtained from a refuse dump at the local Choba main market, Port Harcourt, Nigeria. Typical waste shells of the African giant snail are shown in Figure 1.

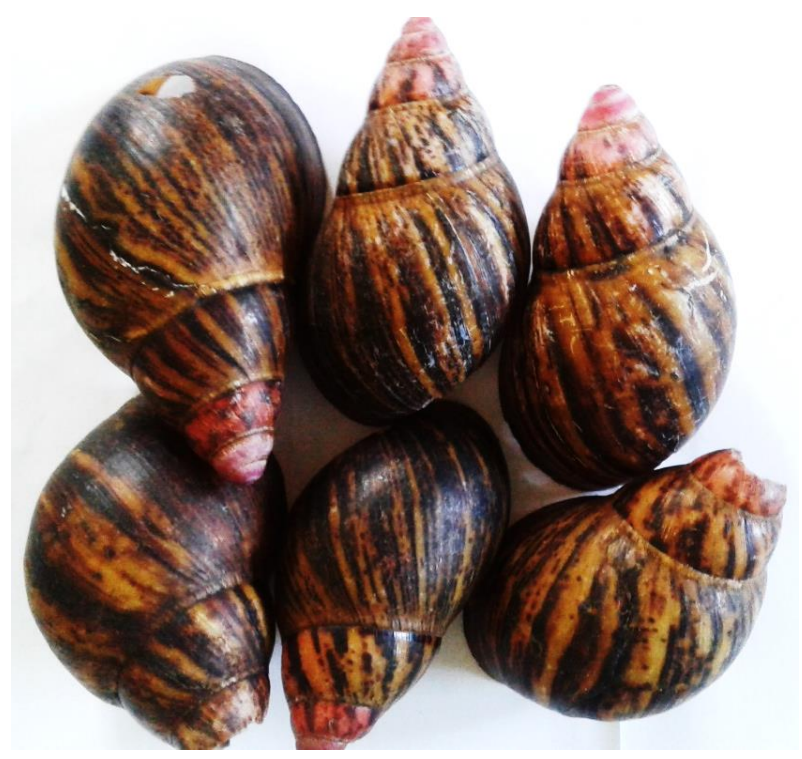

(a)

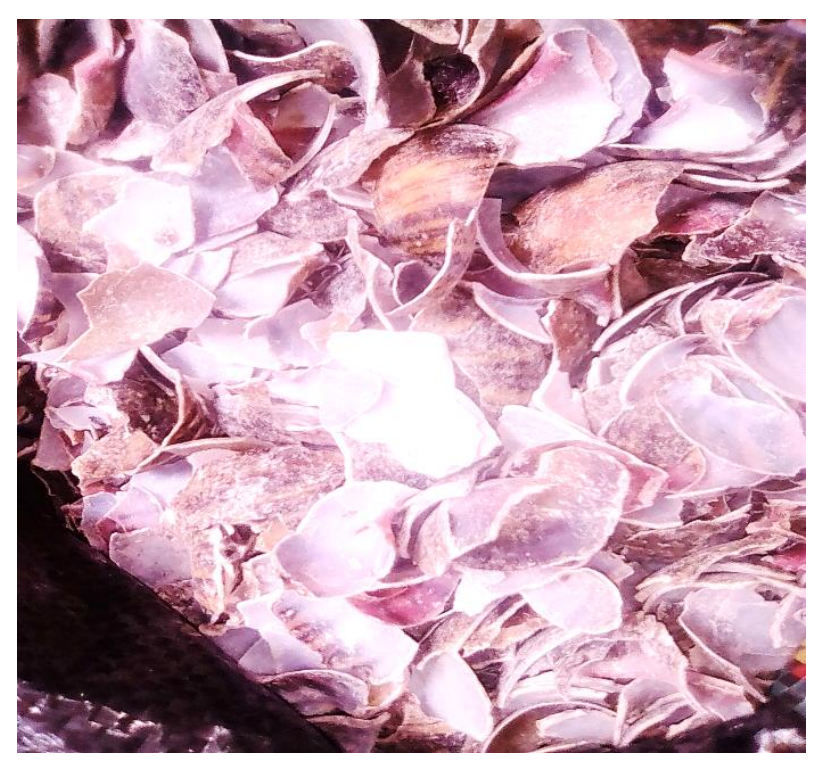

(b)

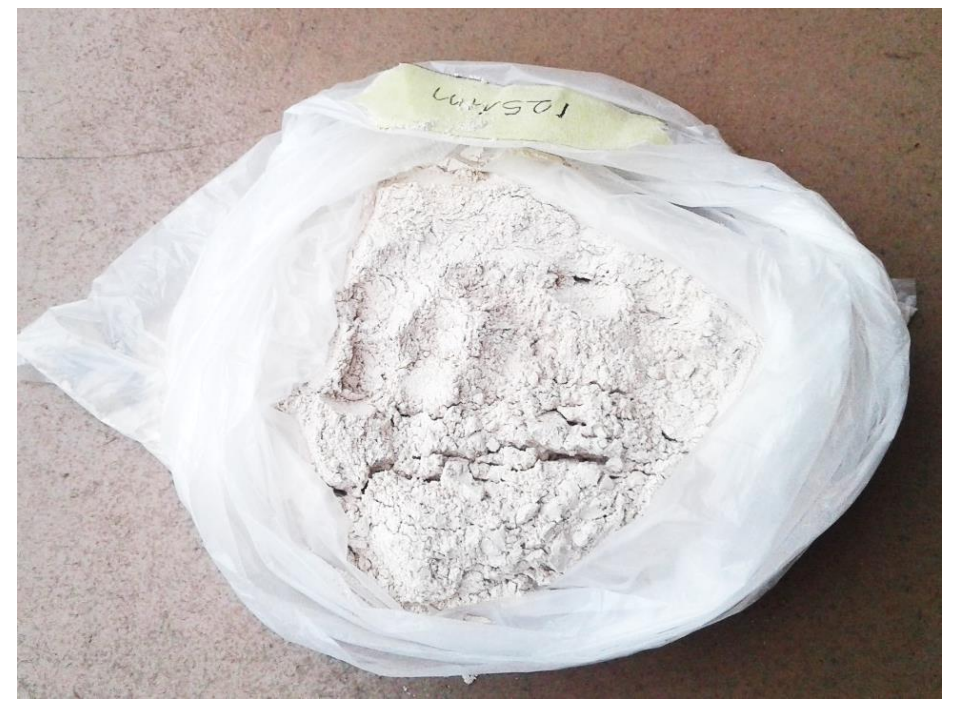

( c )

Figure 1: Waste shells of African Giant Snail in (a) gathered, (b) crushed, (c) grinded conditions 
The chemical reagents applied in formulating the SS-based brake pads matrix are: (a) milky phenol formaldehyde (99\% purity) (Dachy polymer, Taiwan) used as resin, (b) whitish calcium carbonate, $\mathrm{CaCO}_{3}$, (99.5\% purity) (Skyline chemical, USA) used as filler, (c) colourless methyl-ethyl ketone peroxide - MEKP (99\% purity) (Akzonobel, China) used as accelerator, (d) purple cobalt naphanate (99\% purity) (Akzonobel, China) used as catalyst, (e) carbon black (99.9\% purity) (Loba chemie, India) used as friction modifier, and (f) iron fillings used to boost thermal conductivity.

Others include: (a) distilled water, (b) Engine oil (SAE 40 Oil), brake pad mould fabricated from carbon steel plate, Vernier caliper, weighing balance, hardness tester, crushing machine, Sieves of different sizes, milling machine, and electric oven.

\subsection{Methods}

\subsubsection{Development Process}

The procedure and processes used in the development of the sample brake pads is similar to that used by Ossia et al [3] in the production of brake pad samples from waste coconut (cocos nucifera L.) shells as in Figure 2.

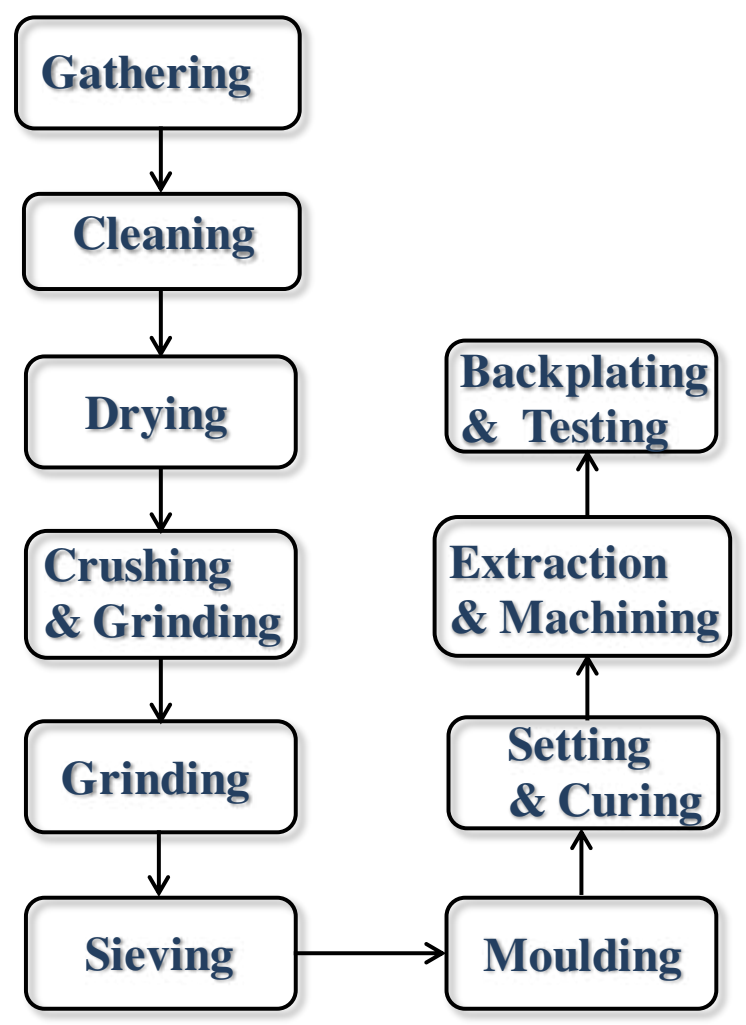

Figure 2: SS-based brake pad sample development process (Ossia et al., [3])

(a) Gathering / Washing / Cleaning: The waste snail shells was gathered at Choba market, Port Harcourt, Nigeria to get the required quantity. The snail shells was thoroughly washed and cleaned to remove dirt and bad smell.

(b) Drying / Crushing / Grinding: The snail shells were dried in sunlight for 3days to reduce their moisture content; then the snails where crushed into smaller pieces and grinded in the laboratory using a grinding machine. 
(c) Sieving: The grinded snail shells were separated into different grain sizes $(90 \mu \mathrm{m}, 125 \mu \mathrm{m}$, $250 \mu \mathrm{m}, 300 \mu \mathrm{m}$ and $500 \mu \mathrm{m}$ ); and separated into different bags with their grain size labels. This process involved arranging the sieves in descending order, applying a quantity of the grinded snail shell in the largest sieve size at the top. The top sieve is covered with the sieve pan cover and shaking vigorously for $10 \mathrm{~min}$ to separate the grinded snail shells at the top to different particle sizes; the quantity left in every sieve size at the end of the 10min is put in a pan with its label.

(d) Moulding / Mixing: The mould was designed with solidworks software and fabricated in University Engineering Workshop. The process involves cutting into shape and welding. The formulation from Table 1 was used; a clean bowl was used in mixing the formulation which was stirred thoroughly to have a homogenous mixture. The binder was added last to avoid the mixture getting hard before leaving the bowl. The mixture was poured into the mould and rammed so the mixture fully occupies the mould.

(e) Setting / Curing: The laboratory brake pad was cured in an electric oven (Model: GE30) at a temperature of $120^{\circ} \mathrm{C}$ for 2 hours.

(f) Extraction: Extraction was done after leaving the newly made brake pad for 1 day to cool and become very hard. The grease applied before the mixture was poured into the mould helps in separating the sample from the mould.

(g) Machining (milling): The extracted brake pad sample is then machined to shape using a carrot stone and a cutting disk with a spindle speed of $288 \mathrm{rpm}$. The SS-based brake pad samples thus developed were then shaped to size using the milling machine (Model: HURE SA-PU771, France).

Table 1: Material Formulation for the snail shell brake pad sample

\begin{tabular}{lll}
\hline s/N & Materials & Composition (wt \%) \\
\hline 1 & Snail shell & 53.9 \\
2 & Phenol formadyhde (resin) & 25 \\
3 & Calcium carbonate (CaCO3) (filler) & 11.7 \\
4 & Carbon black (friction modifier) & 0.5 \\
5 & Metylethyl ketone (accelerator) & 2.8 \\
6 & Cobalt nephtanate (catalyst) & 2.1 \\
7 & Iron fillings(abrasive) & 5.0 \\
\hline
\end{tabular}

\subsubsection{Evaluation Tests}

The physicomechanical tests involving oil (SAE 40) absorption. Water absorption, density, Brinell hardness, compressive strength and thermal conductivity properties tests were performed on the SS-based brake pad samples following procedures adopted from Ossia et al [3].

Friction and wear tests were performed using Anton Paar GmbH TRB3 Tribometer (version 6.1.19) with $\phi 6 \mathrm{~mm}$ stainless steel ball-on-brakepad disc samples in dry sliding contact. All the tribological tests were performed at ambient temperature and humidity conditions of $29^{\circ} \mathrm{C}$ and $55 \%$, respectively. The brake pad samples were turned into a rotating disc sliding against a 
stationary ball loaded with $8 \mathrm{~N}$ at $10 \mathrm{~cm} / \mathrm{s}$ sliding speed in accordance with ASTM procedure [8]. The friction histories of the interface were recorded, as well as, the wear scar area and wear rates.

\section{Results and Discussion}

\subsection{Absorption Test}

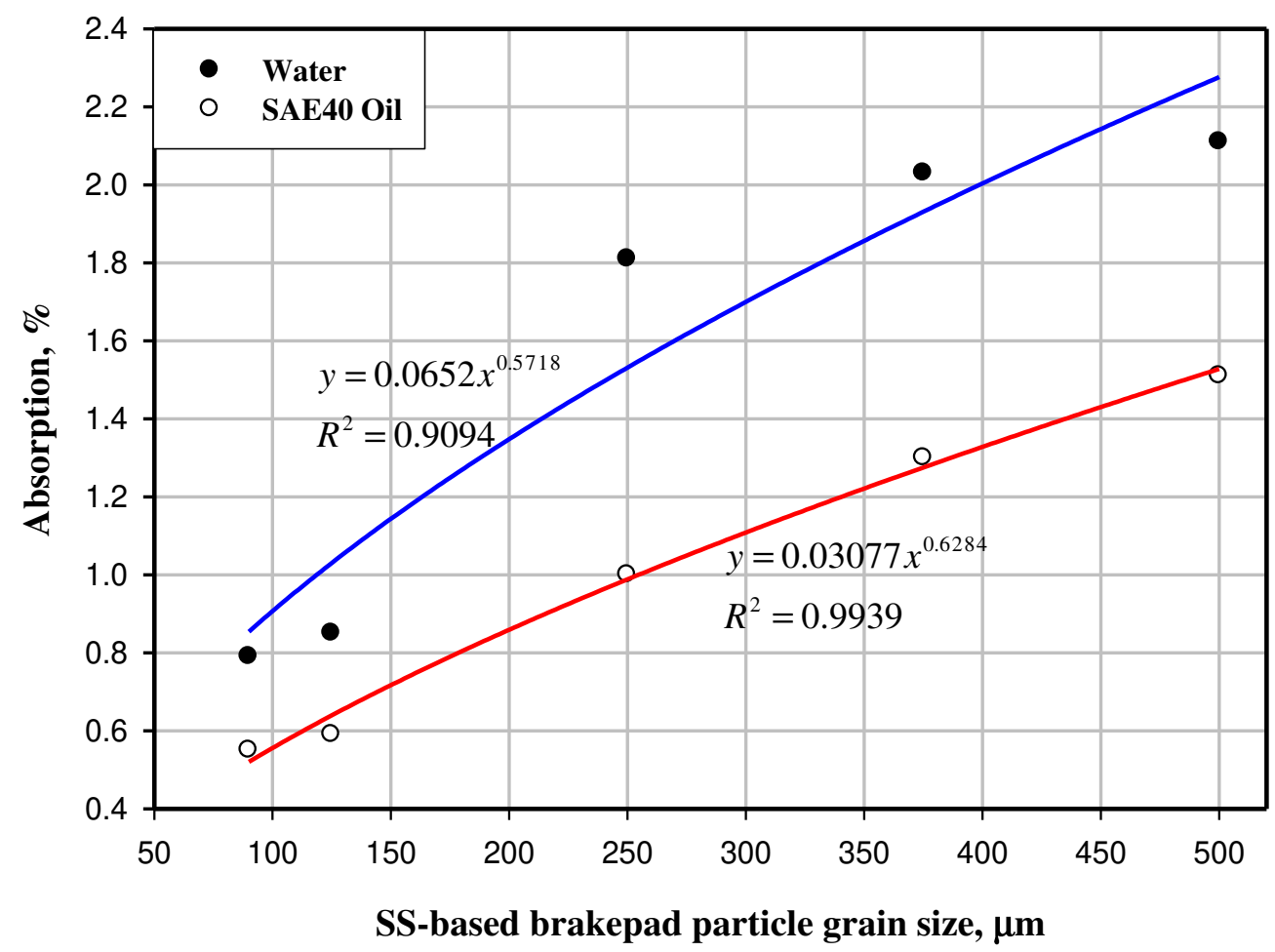

Figure 3, Absorption in Oil and water for SS-based Brakepads with different particle grain sizes

From Figure 3 it was shown that oil absorption of the SS-based brake pad sample increased with increasing grain size. This can be attributed to better bonding between the smaller grain sizes and the binder. When compared with the commercial brake pad, all the developed samples did better. The sample brake pad will do better than the commercial brake pad when there is hydraulic oil leakage.

Also, the water absorption of the sample brake pad increased with increasing grain size. This can be attributed to better bonding between the smaller grain sizes and the binder. When compared with the commercial brake pad the $90 \mu \mathrm{m}$ and $125 \mu \mathrm{m}$ sample did better than the commercial brake pad (with $1.2 \%$ absorption in water and $6.1 \%$ absorption in SAE40 Oil). The sample brake pad will do better than the commercial brake pad if used in a wet environment, for instance, when an automobile goes through a flooded road.

The absorption variation with respect to particle grain size corroborates conclusions of previous studies [2], [9], [10], [4], [3]. The present results show that the absorption property of the control (commercial) brake pad in SAE40 oil was poor compared to those of the SS-based brake pad. 


\subsection{Density}

Figure 4 shows a variation of the density of the SS-based brakepad with particle grain size. The decrease in density can be attributed to the increase in pore size derived from increased aggregate particle size. The $90 \mu \mathrm{m}$ has the highest density $\left(1.74 \mathrm{~g} / \mathrm{cm}^{3}\right)$ which is as a result of closer packing of snail shell aggregate creating more homogeneity in the entire phase of the composite body. Similar decrease in brake pad density with increase in particle grain size had been reported by Yawas et. al. [6] who used periwinkle shells.

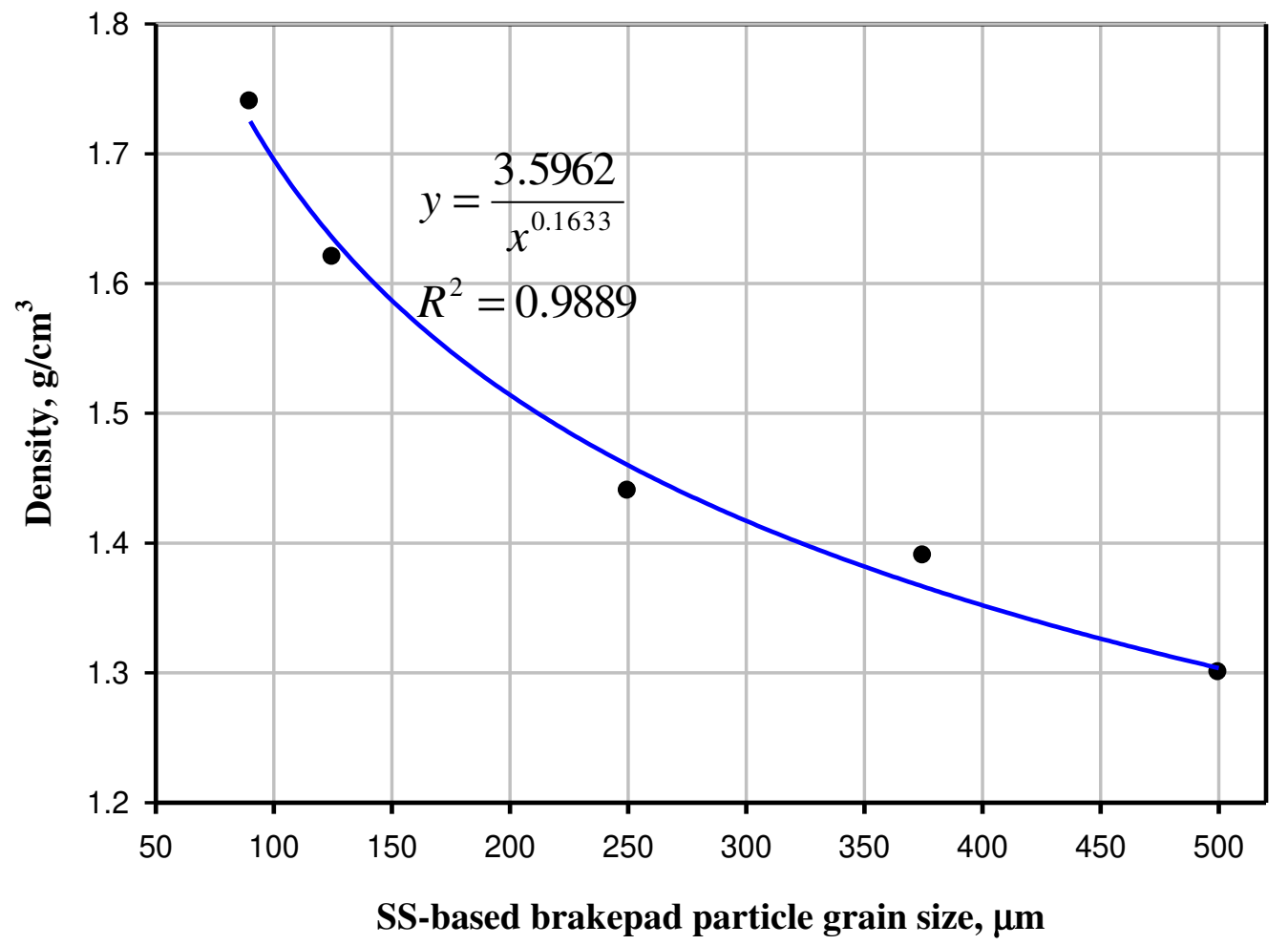

Figure 4, Density of SS-based brake pad for different particle grain sizes

From Figure 4, the densities of all SS-based brake pad samples were lower than the control brake pad density $\left(2.18 \mathrm{~g} / \mathrm{cm}^{3}\right)$. This makes the SS-based brake pad lighter and brings about a reduction in the mass of the automotive braking assembly.

\subsection{Hardness (Brinell)}

The Figure 5 shows that the hardness of sample brake pad varies with increase in grain size. The $90 \mu \mathrm{m}$ sample has the highest hardness value of 49BHN. A sharp drop in hardness was observed in the samples with higher grain sizes $(125 \mu \mathrm{m}),(250 \mu \mathrm{m}),(375 \mu \mathrm{m})$ and $(500 \mu \mathrm{m})$. The high hardness for the $90 \mu \mathrm{m}$ particle size sample is attributable to the increase in particle surface area which resulted to increased bonding with the polyester resin. This corroborates the results of Yawas et. al. [4] who observed a similar trend with periwinkle shells. It can be observed from Figure 4 that the hardness of the samples developed from $90 \mu \mathrm{m}$ and $125 \mu \mathrm{m}$ particle grain sizes (49BHN and 41BHN, respectively) were greater than the hardness of the control brake pad (39BHN). 


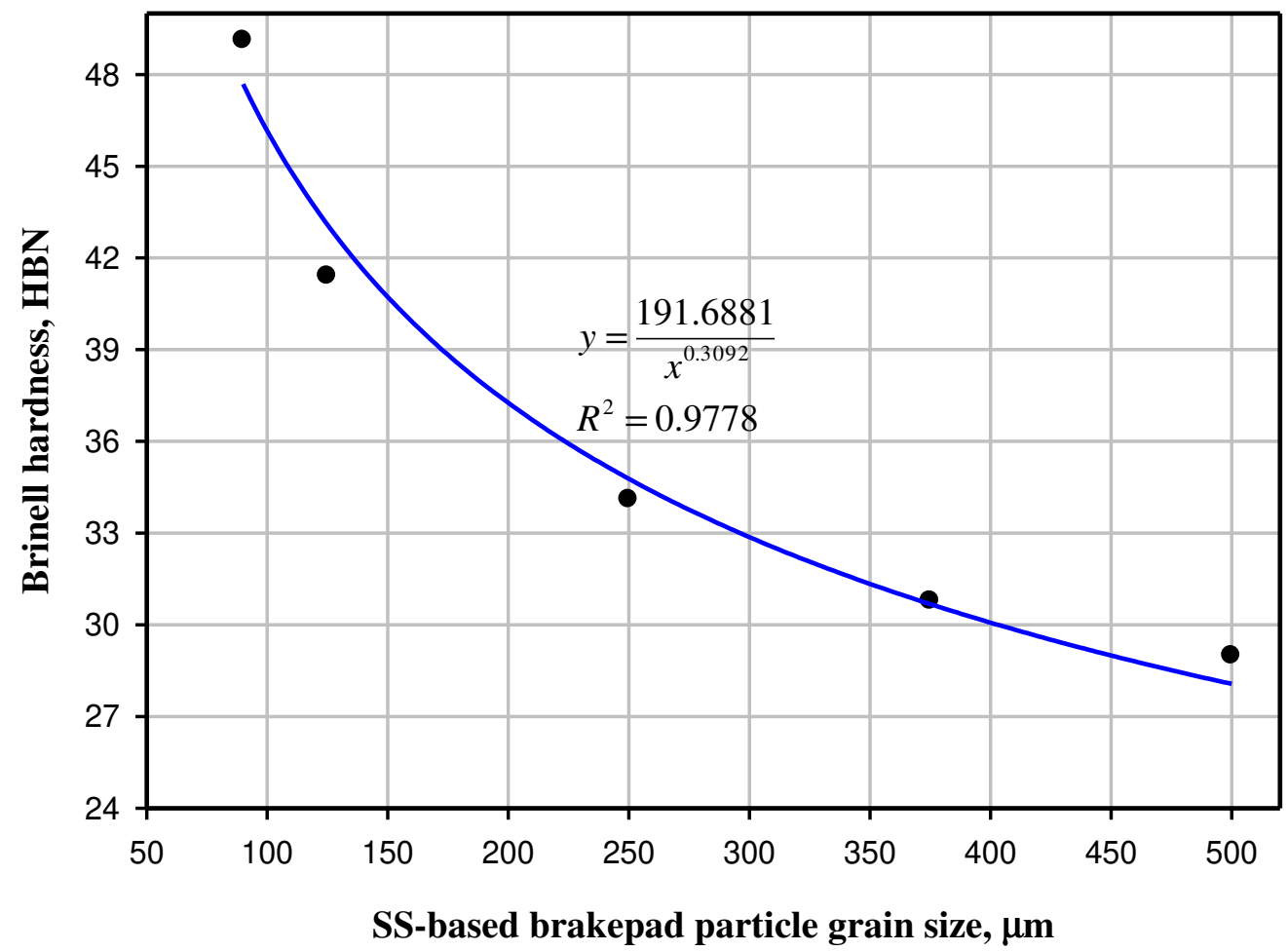

Figure 5: Hardness of experimental brake pads compared with commercial brake pad

\subsection{Compressive strength}

Figure 6 shows the variation of compressive strength with grain size of the sample brake pad. From the results obtained it was observed that the compressive strength increases with decrease in grain size of the specimen. The $90 \mu \mathrm{m}$ sample had the highest compressive strength $(3.77 \mathrm{MPa})$, which was greater than that of the control brake pad (2.85MPa). The gradual decrease in compressive strength as the aggregate increases can be attributed to the decreasing surface area and pore packaging capability of the snail particles in the phenol formaldehyde resin.

Hence, compressive strength increases as aggregate size of the snail shell decreases. During braking, the brakes are exposed to continuous compressive force and the result show that the $90 \mu \mathrm{m}$ sample will do well under such conditions. The observed trend in the relationship between compressive strength and grain size is corroborated by the conclusions of Yawas et al [4] and Jaya et al [6]. 


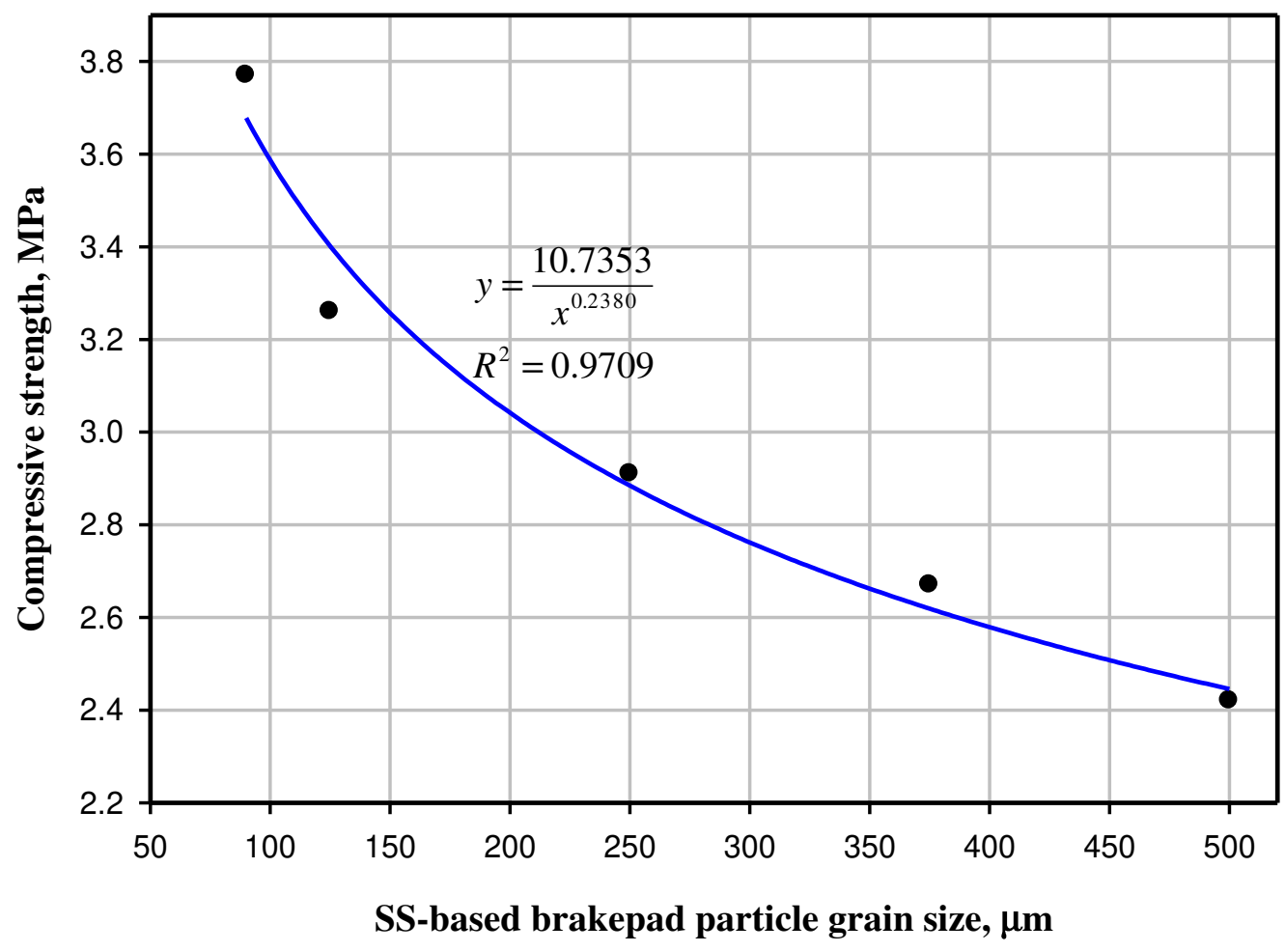

Figure 6: Compressive Strength of the SS-based brake pads with different particle grain sizes

\subsection{Thermal conductivity Test}

Thermal conductivity is an important consideration in the design of a brake pad. Figure 7 shows how the sample brake pad thermal conductivity compares to that of the commercial brake pad. The commercial brake pad had thermal conductivity $(2.02 \mathrm{Wm} / \mathrm{k})$ superior to the sample brake pad $(1.81-1.84 \mathrm{Wm} / \mathrm{k})$. The thermal conductivity appears not to be significantly affected by the increase in the grain size. The thermal conductivity of the sample brake pad can be improved by introducing particles of strong (hard) metallic conductors in its formulation. 


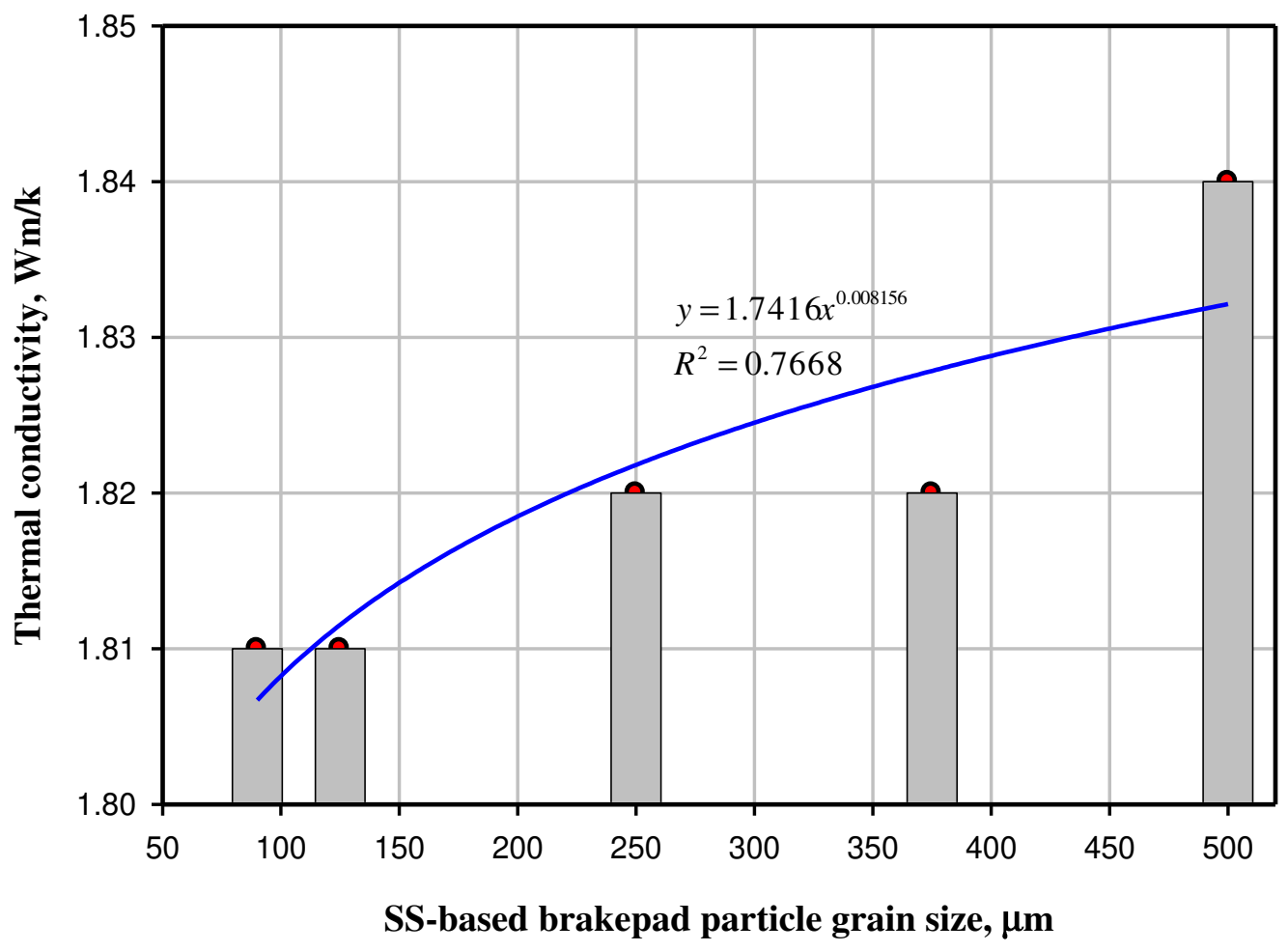

Figure 7: Thermal conductivity of SS-based brakepads with different particle grain sizes

\subsection{Modeling green brake pads Mechanical Properties variation with SS-Particle size}

To model the influence of snail shell particle size on the mechanical properties of the developed green brake pad, a modified form of the classic Hall-Petch equation was adopted. Morris [11] proposed an inverse proportionality relationship with respect to the square root of the grain size diameter (d) and material constants $\left(\mathrm{Ky}\right.$ and $\sigma_{\mathrm{o}}$ ) to explain the influence of grain size on the mechanical properties $\left(\sigma_{\mathrm{y}}\right)$ of metals. Morris' model is a form of the classic Hall-Petch equation and is shown in equation (1).

$\sigma_{y}=\sigma_{o}+\frac{k_{y}}{d^{1 / 2}}$

Morris [12] reported that in nanometals the increase of mechanical properties with respect to decrease in grain size (d) continues to a peak at about $20 \mathrm{~nm}$ grain size (d) beyond which a fall in properties prevails. Hence, two regimes of property variation were reported, namely: regime I for $0 \leq \mathrm{d} \leq 20 \mathrm{~nm}$ (inverse Hall-Petch effect regime where the property decreases with decreasing grain size); and regime II for $\mathrm{d} \geq 20 \mathrm{~nm}$ (Hall-Petch effect regime where the property decreases with increasing grain size).

Other exponents apart from $x=1 / 2$ have been reported for the Hall-Petch model. Different $x-$ exponents in the range $0<\mathrm{x} \leq 1$ have been reported based on experiments. Dunstan and Bushby [13] obtained $\mathrm{x}=1$ for FCC and BCC metals and ceramics in the compression testing of micropillars by using grain size as bulk micropillar diameters (d) which was corroborated by Li et 
al [14]. Agraie-Khafri et al. [15] reported x = 0.66 for hot rolled AISI 300 stainless steel in uniaxial tensile tests at $0.2 \%$ strain..

In this study, the mechanical properties, $y_{p}$, of the sample brake pad were modeled by power law relationship after the order of a modified Hall-Petch equation (2).

$y_{p}=\frac{K_{p}}{X^{a}}$

where; $X \quad$ - $\quad$ Particle size value $(\mu \mathrm{m})$ equivalent to Hall-Petch grain size $(\mathrm{d})$;

$\mathrm{k}_{\mathrm{P}} \quad$ - $\quad$ particle size constant;

a - $\quad$ particle size index equivalent to Hall-Petch grain exponent (1/2);

The mechanical property results obtained in Figures 2 to 5 were modeled by power law for bestfit after 100-iterations using SigmaPlot-8 software. The models obtained for the mechanical properties, their R-value and error estimate are summarized in Table 2.

Table 2: Models of mechanical properties of SS brake pad samples as functions of particle size

\begin{tabular}{|c|c|c|c|c|c|}
\hline $\mathrm{s} / \mathrm{N}$ & $\begin{array}{c}\text { Mechanical } \\
\text { Property }\end{array}$ & Mathematical Model & $\begin{array}{c}\text { Coefficient of } \\
\text { determination } \\
\mathrm{R}^{2}\end{array}$ & $\begin{array}{c}\text { Standard } \\
\text { Error of } \\
\text { Estimation } \varepsilon\end{array}$ & p-value \\
\hline 1 & $\begin{array}{l}\text { Oil } \\
\text { Absorption, } \\
\text { Ao }\end{array}$ & $A_{o}=0.03077 X^{0.6284}$ & 0.9939 & 0.0383 & 0.0002 \\
\hline 2 & $\begin{array}{l}\text { Water } \\
\text { Absorption, } \\
\text { Aw }\end{array}$ & $A_{w}=0.06516 X^{0.5718}$ & 0.9094 & 0.2248 & 0.0119 \\
\hline 3 & Density, $\rho$ & $\rho=\frac{3.5962}{X^{0.1633}}$ & 0.9889 & 0.0217 & 0.0005 \\
\hline 4 & Harness, BHN & $B H N=\frac{191.6881}{X^{0.3092}}$ & 0.9778 & 1.4335 & 0.0041 \\
\hline 5 & $\begin{array}{l}\text { Compressive } \\
\text { strength, } \sigma_{c}\end{array}$ & $\sigma_{c}=\frac{10.7353}{X^{0.23803}}$ & 0.9709 & 0.1039 & 0.0021 \\
\hline 6 & $\begin{array}{l}\text { Thermal } \\
\text { conductivity, } \mathrm{k}\end{array}$ & $k=1.7416 x^{0.008156}$ & 0.7668 & 0.0068 & 0.0516 \\
\hline
\end{tabular}

The nonlinear regression of thermal conductivity with particle grain size is rather weak because of the lower coefficient of determination $\mathrm{R}^{2}=0.7668$.

It is instructive to observe that all mechanical property models in Table 2 are similar, following a power law with a positive or negative particle size index, indicating similar generating mechanism. It showed positive particle size indices for oil absorption, water absorption and thermal conductivity (flow processes) and negative particle size indices for density, hardness and compressive strength (non-flow processes). These properties are attributable to the roles of pores in the composite matrix. The higher the matrix particle size, the higher the pore size and distribution that enhance absorption as the pores are being filled in the soaking (absorption) medium. But the corollary is true for other mechanical properties, since the higher pores associated 
with higher matrix particle sizes become crack nucleation sites in the course of loading before failure in hardness or compression test. Hence, higher particle sizes become associated with lower hardness and compressive strength. Obviously, for a fixed volume of brakepad matrix the sample with higher particle size, hence higher pores sizes and distribution will exhibit less mass, and hence less density which corroborates the model result. This explains the results earlier obtained by Dagwa et al [2], Yawas et al [4], Zykova et al [9], Ameh et al [10] and Jaya et al [6].

\subsection{Tribological Performance Characterization}

\subsubsection{Friction characterization of the Ball-on-Disc sliding contact}

\section{(a) Friction history}

The friction history, which is a measure of kinetic friction trace of all the developed brake pad samples showed 2 friction regimes, namely: the transient and steady state regimes. The transient regime is characterized by friction rise from zero (or minimum value) to the onset of steady state value. From Figure 8 to Figure 13, when the steady state value is attained the kinetic friction remains at this value till the end of the sliding contact. So, the friction signatures in Figure 8 to Figure 13 can be observed to follow through a minimum, average and maximum friction values for every friction trace. While the friction mechanism in the transient regime could be explained by the surface roughness (asperity interlock) friction theory [16], that of the steady state regime can be explained by the simple adhesion friction theory due to the filling of the matrix pores close to the interface by initial wear metal transfer.

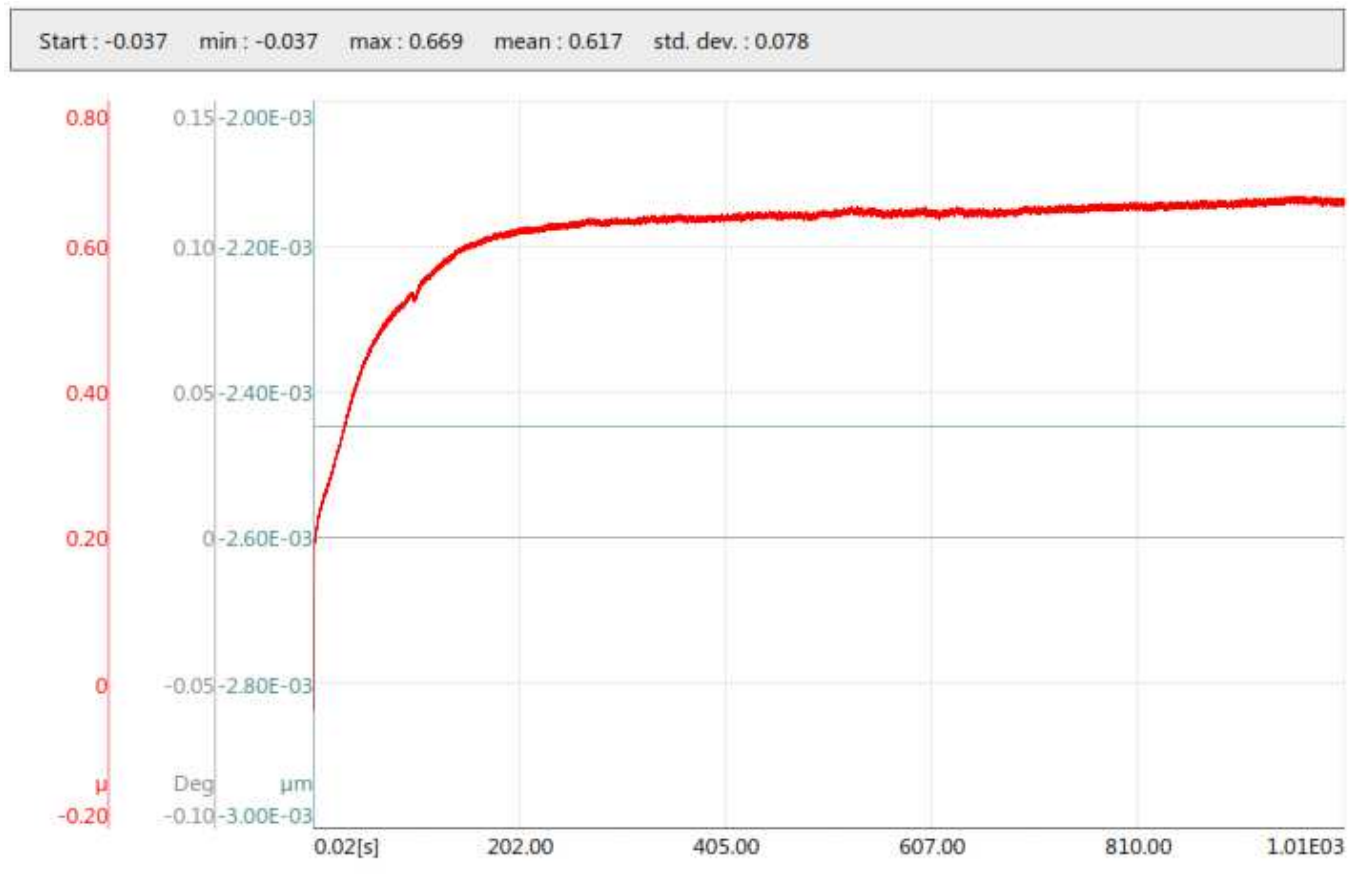

Figure 8, Friction history of SS-based Brake pad sample with $90 \mu \mathrm{m}$ particle size 


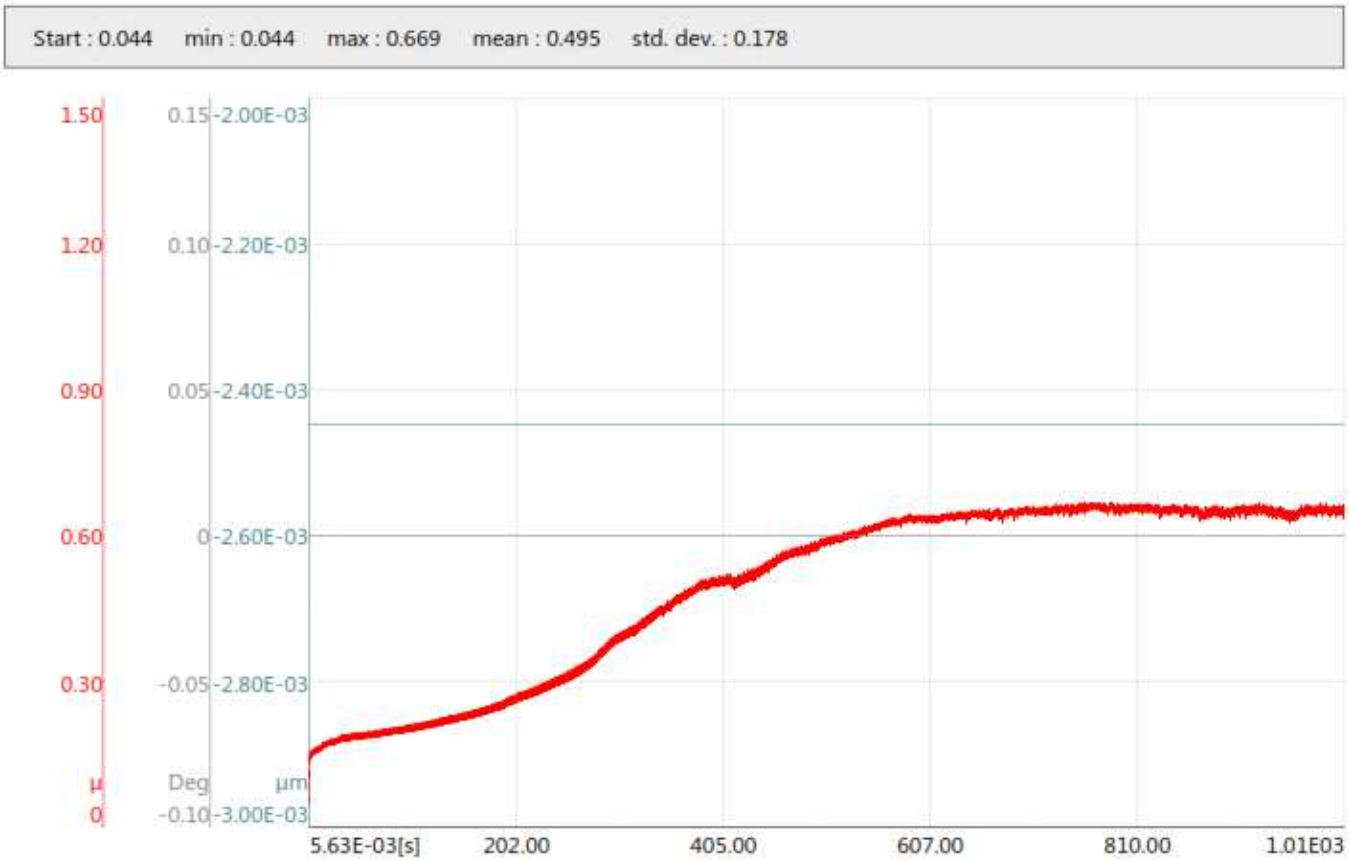

Figure 9, Friction history of SS-based Brake pad sample with $125 \mu \mathrm{m}$ particle size

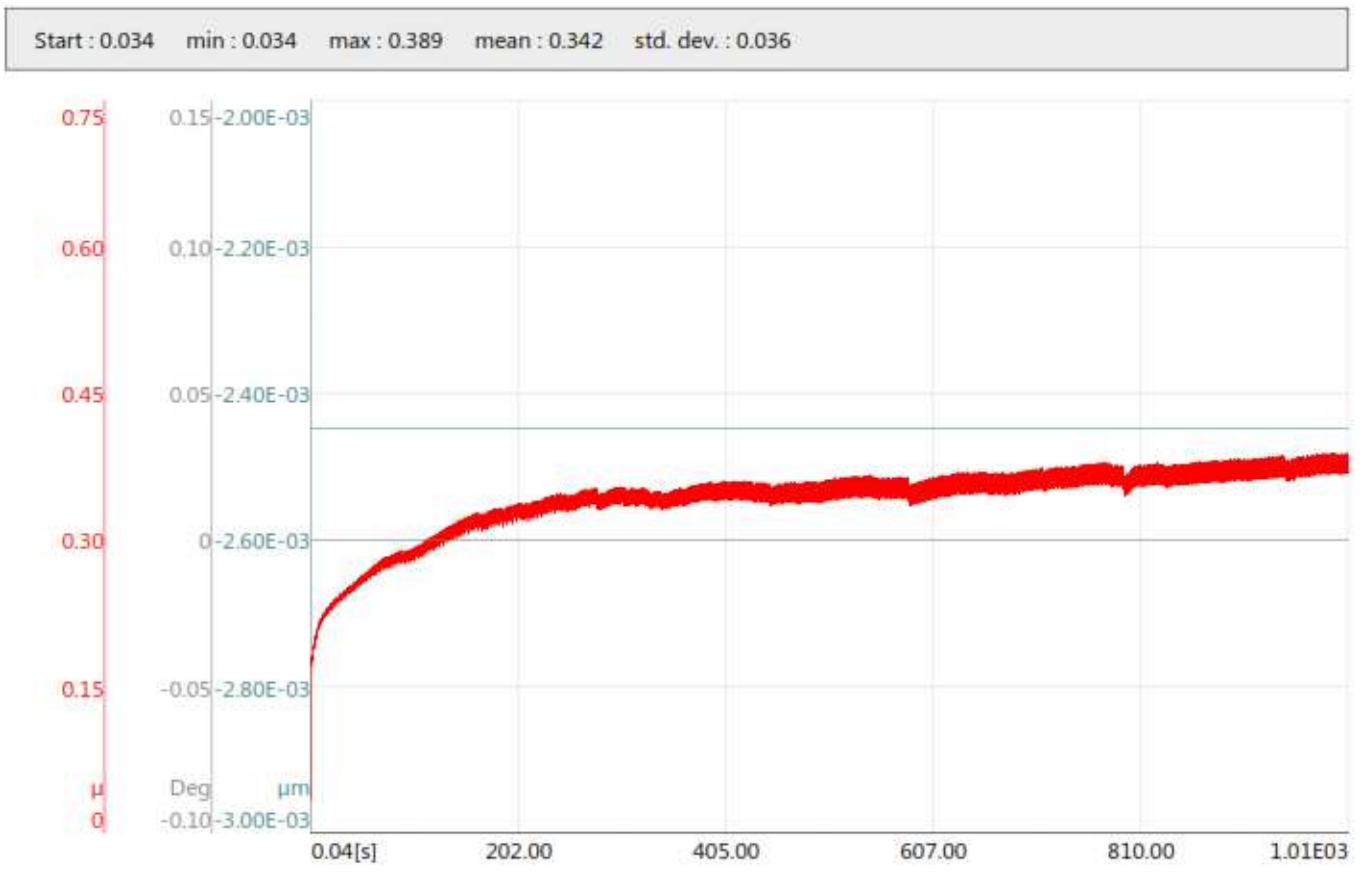

Figure 10, Friction history of SS-based Brake pad sample with $250 \mu \mathrm{m}$ particle size 


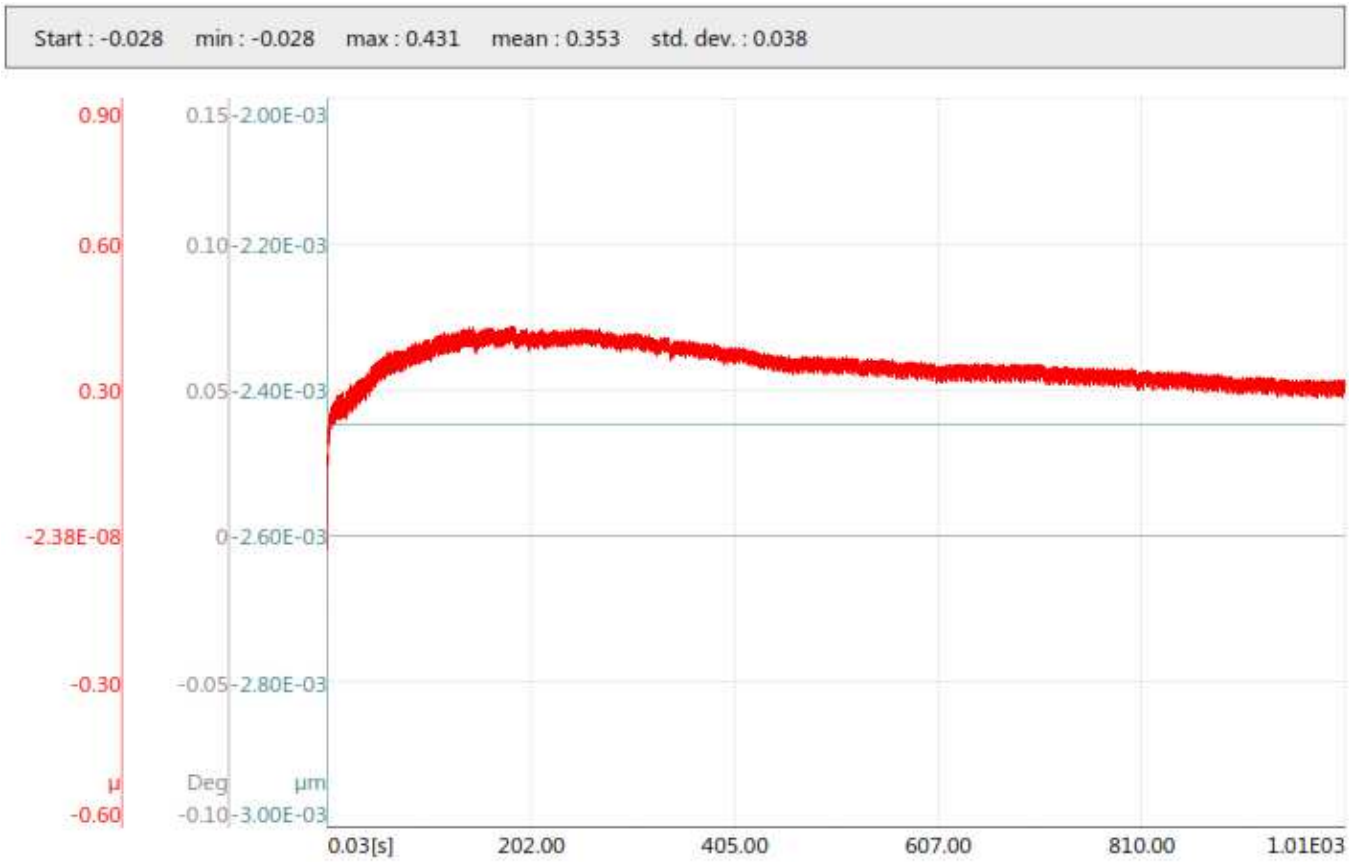

Figure 11, Friction history of SS-based Brake pad sample with $375 \mu \mathrm{m}$ particle size

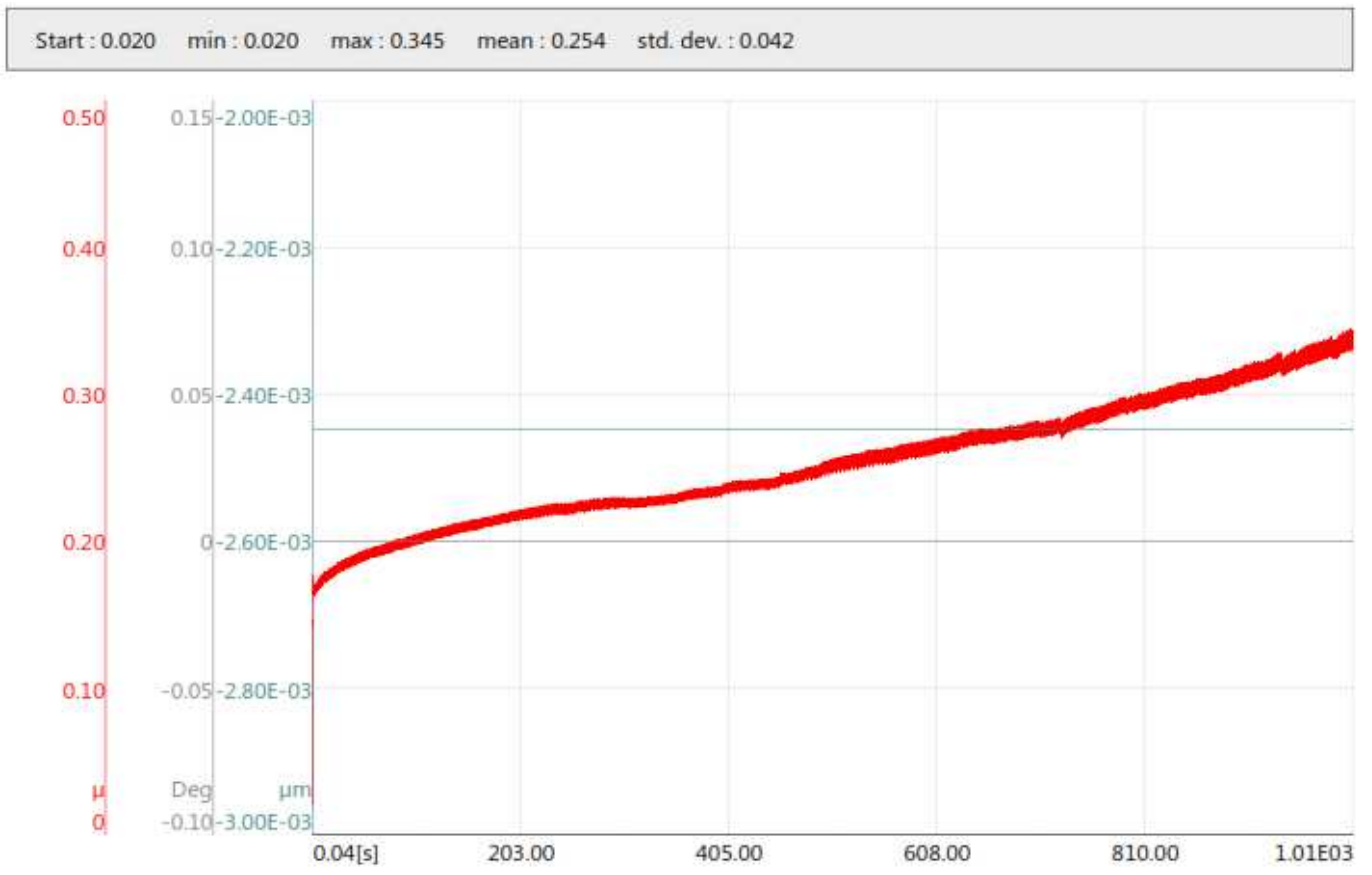

Figure 12, Friction history of SS-based Brake pad sample with 500 $\mu \mathrm{m}$ particle size 


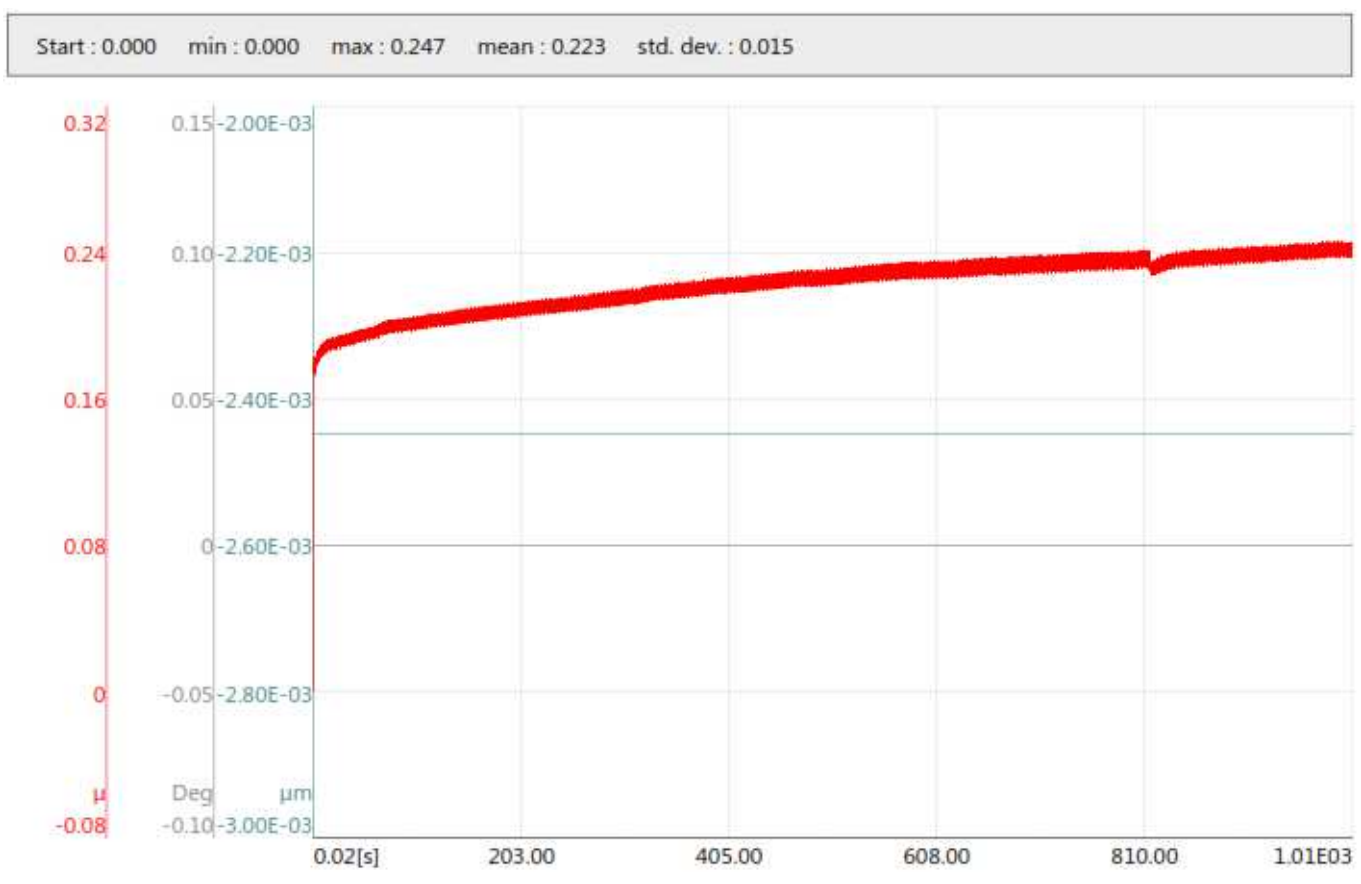

Figure 13, Friction history of the control brake pad sample

\section{(b) Average friction Coefficient}

Figure 14 shows the average friction coefficient for the sliding contact of a steel ball sliding on the brake pad disc in a 1010 secs test. The results showed increase in friction coefficient with increase in particle grain size. The friction coefficient of the commercial sample was less than that of the highest grain size sample, that is, the $500 \mu \mathrm{m}$ grain size sample. This result is in contrast with Yawas et al [4] result based on periwinkle shells, but corroborated that of Amaren et al [5] who studied the effect of periwinkle particle size on the wear of brake pad using full factorial experimental design. Amaren et al [5] obtained a negative main effect (-0.025) of periwinkle particle size on friction coefficient models for brake pads. Of all the 4 independent variables (load, speed, temperature, and particle size) used to model friction and wear in the study, particle size was the most significant (p-value 0.02777). This friction coefficient variation trend with respect to particle size was also observed by Sasaki [17] and Aigbodion et al. [18].

From the friction values in Figure 14 and based on the work of Blau [19] and SAE J866a [20] standards for friction identification of brake linings and brake blocks, the commercial brake pad can be rated as Edge Code-D whereas the $500 \mu \mathrm{m}$ sample is Edge-Coded-E, $375 \mu \mathrm{m}$ sample is EdgeCoded-F, 250 $\mu \mathrm{m}$ sample is Edge-Coded-E, $125 \mu \mathrm{m}$ sample is Edge-Coded-G and $90 \mu \mathrm{m}$ sample is Edge-Coded-H. Finally, the frictional responses in Figure 14 suggest that the green brake pads offer better or more effective grip at the rubbing interface relative to the commercial brake pads. This frictional property improved with decreasing particle size.

The average friction coefficient $\mu_{\text {ave }}$ was modeled as equation (3).

$\mu_{\text {ave }}=\frac{5.01326}{x^{0.4716}}$ 


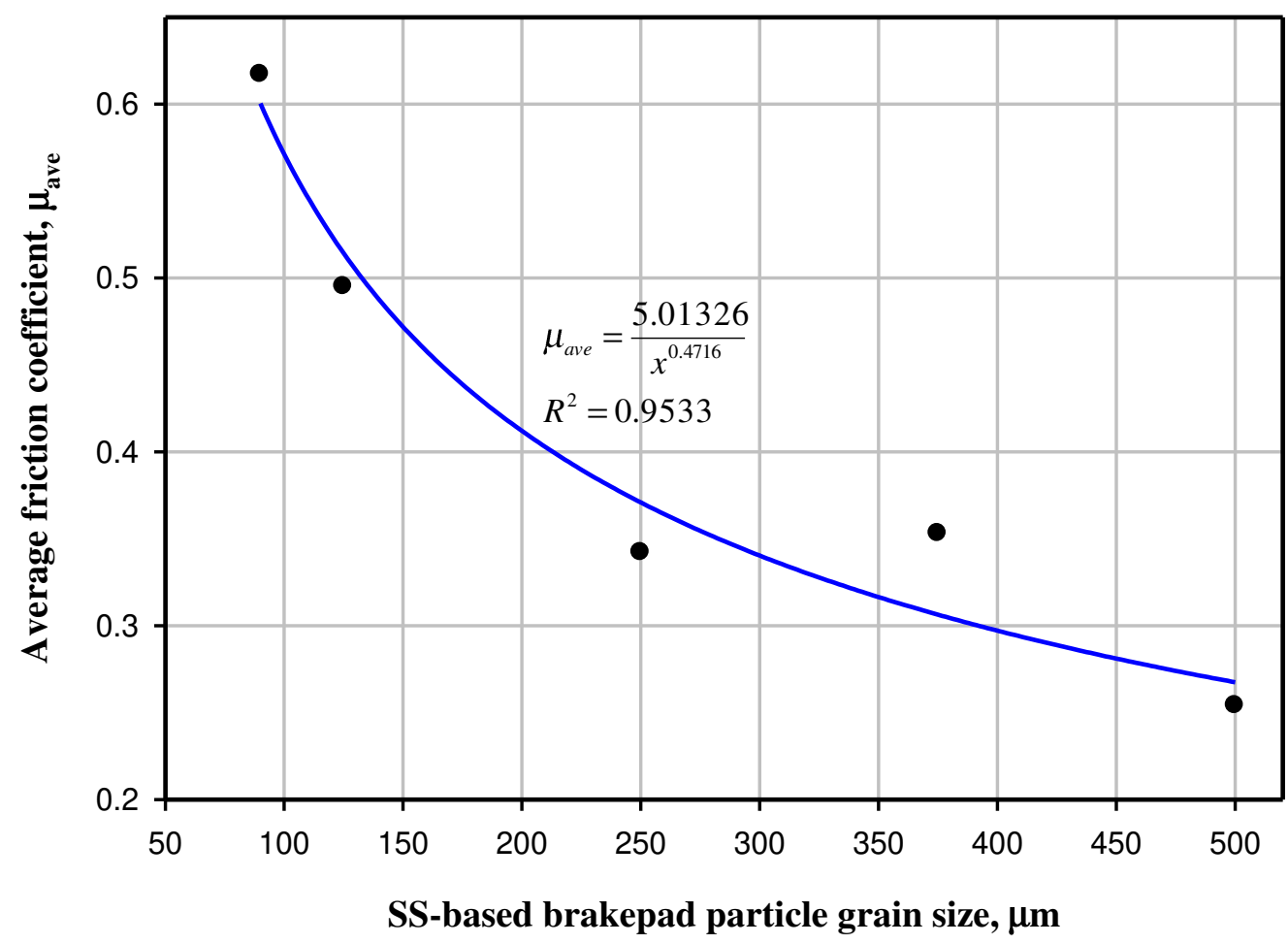

Figure 14, Average friction coefficient of SS-based brake pad samples with different grain sizes Where coefficient of determination $R^{2}=0.9533$, standard error of estimate $=0.0358$, and $\mathrm{p}$-value $=0.0043$. It is obvious that as the particle size increases, the average friction coefficient decreases, hence corroborating Amaren et al [5] negative effect.

\subsubsection{Wear Characterization of green brake pads using ball-on-disc sliding contacts}

The wear rates and wear areas of the worn brake pads were observed to decrease with the increase in snail-shell granular particle size as in Figure 15. All SS-based brake pad samples exhibited higher wear rates and wear surface areas compared to the control brake pad. This is attributable to the poor thermal conductivity of the sample brake pads which made them thermally unstable during the friction heating of the rubbing contacts. This poor wear behavior can be compensated by impregnating the composite matrix of the sample brake pads with higher percentage of iron fillings to obtain better frictional grip with reduced wear rates and wear surface.

The wear area was modeled as equation (4).

$W_{\text {area }}=55.8769-0.01977 x^{1.1469}$

Where coefficient of determination $\mathrm{R}^{2}=0.9828$, standard error of estimate $=1.6631$ and $\mathrm{p}$-value $=0.0172$. Also, the wear rate model was obtained as equation (5).

$W_{\text {rate }}=250.717-1.859 x^{0.6934}$

Where coefficient of determination $\mathrm{R}^{2}=0.9384$, standard error of estimate $=14.7525$ and $\mathrm{p}$-value $=0.0616$. Comparing equation (4) and equation (5) with equation (1), it can be observed that wear rate and wear are models followed the classical Hall-Petch equation with negative particle 
constants $\mathrm{k}_{\mathrm{y}}$ and positive particle (grain) size indices since wear particle generating mechanism was by plastic flow due to crack propagation.

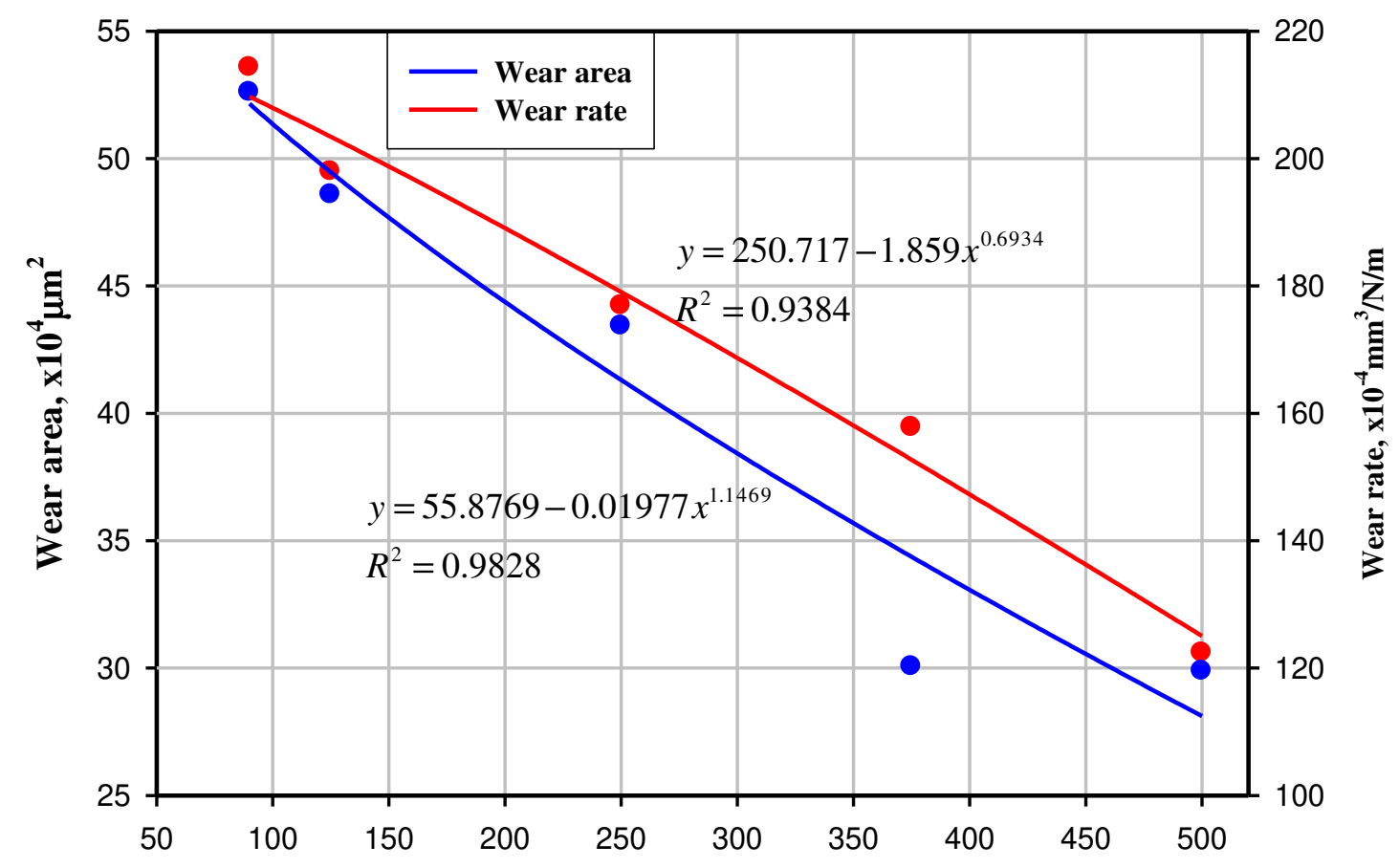

SS-based brakepad particle size, $\mu \mathrm{m}$

Figure 15, Wear characterization of SS-based brake pads with different particle grain sizes

Different scholars attempting to relate wear rates with particle size of specimens have obtained variant results in the recent past. Sevim and Eryurek [21] obtained results showing that wear resistance of non-heat treated steel was inversely proportional to the square root of the abrasive particle size by gravimetric measurement. This is at variance with the results of the present study due to the fact that Sevim and Eryurek [21] considered the particle size of the harder (abrasive) material while the present study focused on the particle size of the softer (abraded) material. Arora et al [22] investigated the influence of particle size and temperature on the wear properties of rutilereinforced aluminum metal matrix composites. They obtained results for a $49 \mathrm{~N}$ load on a pin-ondisc tribometer which indicated that finer particles $(50-75 \mu \mathrm{m})$ exhibited wear resistances that are two orders greater than the corresponding results of composites with coarse particle sizes (106$125 \mu \mathrm{m})$. Santos et al [23] used dimensional change measurement of AISI 1020 steels with Alumina $\mathrm{Al}_{2} \mathrm{O}_{3}$ coatings of different particles sizes $(92 \mathrm{~nm}-76.79 \mu \mathrm{m})$ at $10.2 \mathrm{~N}$ load in the adhesive wear and $130 \mathrm{~N}$ in abrasive wear mode. Their results showed a logarithmic rise of wear volume with respect to particle size which was more pronounced at nanoscale $(<100 \mathrm{~nm})$; but for particle size $>$ $10 \mu \mathrm{m}$ there was little or no particle size effect on wear in both adhesive and abrasive modes. 
A typical finished SS-based brake pad with $125 \mu \mathrm{m}$ particle size mounted on the back-plate ready for installation on a brake-disc is shown in Figure 16.

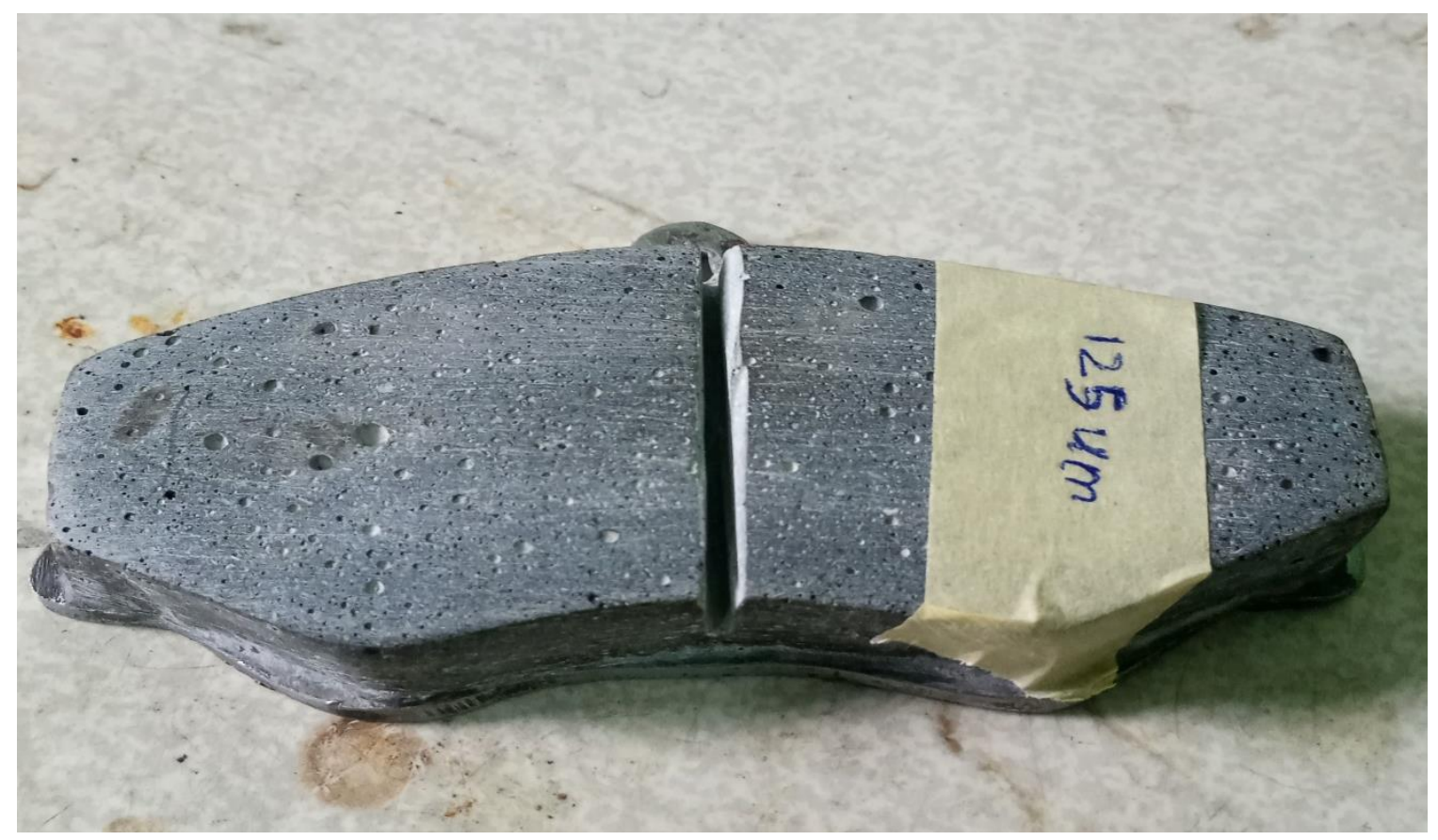

Figure 16: The finished SS-brake pad with $125 \mu \mathrm{m}$ particle grain size

\section{Conclusion}

Experimental evidence in the present study showed that the application of waste African snail shell as base material for brake pads has the potentials of a good replacement for the carcinogenic asbestos-based brake pads. The mechanical properties of the SS-based brake pads, such as density, brinell hardness and compressive strength decreased with increase in particle size, following a power law model with negative power exponent after the order of the Hall-Petch equation. However, the liquid absorption and thermal conductivity properties (flow processes) exhibited models with positive particle size indices. Whereas the absorption of the SS-based brake pads increased with increase in particle size due to the pores in the matrix which increased with particle size, the thermal conductivity showed lower variation with particle size. The SS-based brake pads exhibited better frictional grip at the rubbing interfaces compared to the commercial brake pad. However, the wear behavior was poor compared to the commercial sample. This poor wear behavior can be compensated by impregnating the composite matrix with higher percentage of iron fillings to improve its thermal conductivity and stability.

\section{Acknowledgement}

Edem Ekpeyong Edem, Bola Shakirat Binuyo and Emmanuel Ogheneochuko Ekpruke are deeply appreciated for their efforts in the development and evaluation of the snail-shell-based brake pads.

\section{Declarations}

Ethical Approvals: $\quad$ Ethical approvals are not required for this research work. 
Consent to Participate: Consent is hereby given by Authors for the Journal Editorial / Review Team to participate in the Manuscript Blind-Review Process prior to publication

Consent to Publish: Consent is hereby granted by the Authors for the Editorial Team and Publishers to proceed with the Publication of the Research Manuscript after acceptance

Authors Contribution: The research contained herein describes a green, non-carcinogenic, asbestos-free automotive brake pad derived from biodegradable organic composite of waste snail shells as an alternative to the asbestos-based brake pads. The lead / correspondence author conceptualized, supervised and implemented the research while the second (contributing) author performed the editing.

Funding: No grant or research fund was received for this work.

Competing Interests: To the best of Authors knowledge, there is no conflict of interest or competing interest involved in this research

Availability of Data \& materials: All data generated or analyzed during this study are included in this manuscript and its supplementary files.

\section{References}

[1] Mutlu I. (2009); Investigation of tribological properties of brakepads by using rice straw and rice husk dust; Journal of Applied Sciences 09(02), 377-381, https://doi.org/10.3923/jas.2009.377.381

[2] Dagwa I. M., Builders, P. F., Achebo J. (2012); Characterization of palm kernel shell powder for use in polymer matrix composites, International Journal of Mechanical and Mechatronics Engineering, 2012, Vol. 12(04), p. 88-93.

[3] Ossia C.V., Big-Alabo A., Ekpruke E.O. (2020); "Effect of Particulate Grain size on the Physicomechanical Properties of Green Automotive Brake Pads from Waste Coconut (Cocos Nucifera) Shells", Advances in Manufacturing Science \& Technology - The Journal of the Committee of Mechanical Engineering, Polish Academy of Sciences, Vol. 44(04), PP.135-144. DOI: https://doi.org/10.2478/amst-2019-0023

[4] Yawas, D.S., Aku S.Y., Ammaren S.G. (2016); Morphology and properties of periwinkle shell asbestos-free brakepad. Journal of king Saud University - Engineering Sciences, Vol.28, PP.103-109.

[5] Amaren, S.G. Yawas, D.S. Aku S.Y. (2013); Effect of periwinkles shell particle size on the wear behavior of asbestos free brake pad, Results in Physics, 3:109-114, DOI: 10.1016/j.rinp.2013.06.004

[6] Jaya H., Omar M.F., Md-Akil H., Ahmad Z.A., Zulkepli N.N. (2016); "Effect of particle size on Mechanical properties of sawdust-High density polyethylene composites under various strain rates," BioResources, Vol. 11 (03), 6489-6504. 
[7] Mutuk T. and Gurbuz M. (2019); Effect of pure titanium particle size on density, hardness, wear resistance and microstructure properties; Journal of Metals, Materials and Minerals (JMMM), Vol. 29(03), PP.54-59.

[8] ASTM International (1999); G99-17 Standard test method for wear testing with a pin-on-disk apparatus.

[9] Zykova, A. K.; Pantyukhov, P. V.; Kolesnikova, N. N.; Popov, A. A.; Olkhov, A. A. (2015), Influence of particle size on water absorption capacity and mechanical properties of polyethylene-wood flour composites; AIP Conference Proceedings, October 2015, Vol 1683, Issue 1, id 020242 (2015); https://doi.org/10.1063/1.4932932

[10] Ameh, A.O., Isa M.T., Sanusi I. (2015), Effect of particle size and concentration on the mechanical properties of polyester/date palm seed particulate composites, Leonardo Electronic Journal of Practices and Technologies, Vol 14 (26), January-June 2015 p. 6578.

[11] Morris, J.W. (2001); The Influence of Grain Size on the Mechanical Properties of Steel. Report No: LBNL-47875, Lawrence Berkeley National Laboratory, Office of Scientific \& Technical Information Report, Department of Energy, Berkeley - California, United States of America, PP.1-8, doi:10.2172/861397.

[12] Morris D.G. (2011); Strengthening mechanisms in nanocrystalline metals, in Whang S.H. (Ed) Nanostructured Metals and Alloys, processing, microstructure, mechanical properties and applications; Woodhead Publishing Series in metals and surface engineering, PP.299-328, https://doi.org/10.1533/9780857091123.3.299.

[13] Dunstan D.J., Bushby A.J. (2013); The scaling exponent in the size effect of small scale plastic deformation; International Journal of Plasticity, Vol.40, PP.152 - 162. https://doi.org/10.1016/j.ijplas.2012.08.002

[14] Li Y., Bushby A.J., Dunstan D.J. (2016); The Hall-Petch effect as a manifestation of the general size effect Proceedings of the Royal Society A, Mathematical, Physical and Engineering Sciences.472: 2015-0890 http://doi.org/10.1098/rspa.2015.0890

[15] Aghaie-Khafri M, Honarvar F, Zanganeh S. (2012); Characterisation of grain size and yield strength in AISI 301 stainless steel using ultrasonic attenuation measurements. Journal of Nondestructive Evaluation, Vol. 31, 191-196. (doi:10.1007/s10921-012-0134-z)

[16] Czichos H. (2000); Tribology: A Systems Approach to the Science and Technology of Friction, Lubrication and Wear, $1^{\text {st }}$ edition, Elsevier Science Publishers, United States of America.

[17] Sasaki, Y. (1995), Development Philosophy of Friction Materials for Automobile Disc Brakes. The Eight International Pacific Conference on Automobile Engineering. Society of Automobile Engineers of Japan; Society of Automobile Engineer of Japan, 407-412.

[18] Aigbodion V., Akande U., Hasssn S.B., Asuke F., Agunsoye J.O. (2010), Development of asbestos- free brake pad using bagasse. J Tribol Industry, 32(1):2010. 
[19] Blau, P.J., (2001), “Compositions, Functions, and Testing of Friction Brake Materials and their Additives", A report by Oak Ridge National Laboratory for U.S. Dept. of Energy.

[20] Society of Automotive Engineers - SAE (2012); SAE J866-2012 (SAE J866-2012), Friction Coefficient Identification and Environmental Marking System for Brake Linings

[21] Sevim I., Eryurek I.B. (2006); Effect of abrasive particle size on the wear resistance in steels, Materials \& Design, 27 (03), 173-181. https://doi.org/10.1016/j.matdes.2004.10.010

[22] Arora R., Kumar S., Singh G., Pandey O. (2015); Influence of particle size and temperature on the wear properties of rutile-reinforced aluminium metal matrix composite, Vol. 49(07), PP.843-852. https://doi.org/10.1177/0021998314526079

[23] Santos A., Guzmán R., Ramirez Z Y. (2017); Influence on the wear resistance of the particle size used in coatings of Alumina; Journal of Physics: Conference Series 786 (2017) 012012, doi:10.1088/1742-6596/786/1/012012. 


\section{Figures}

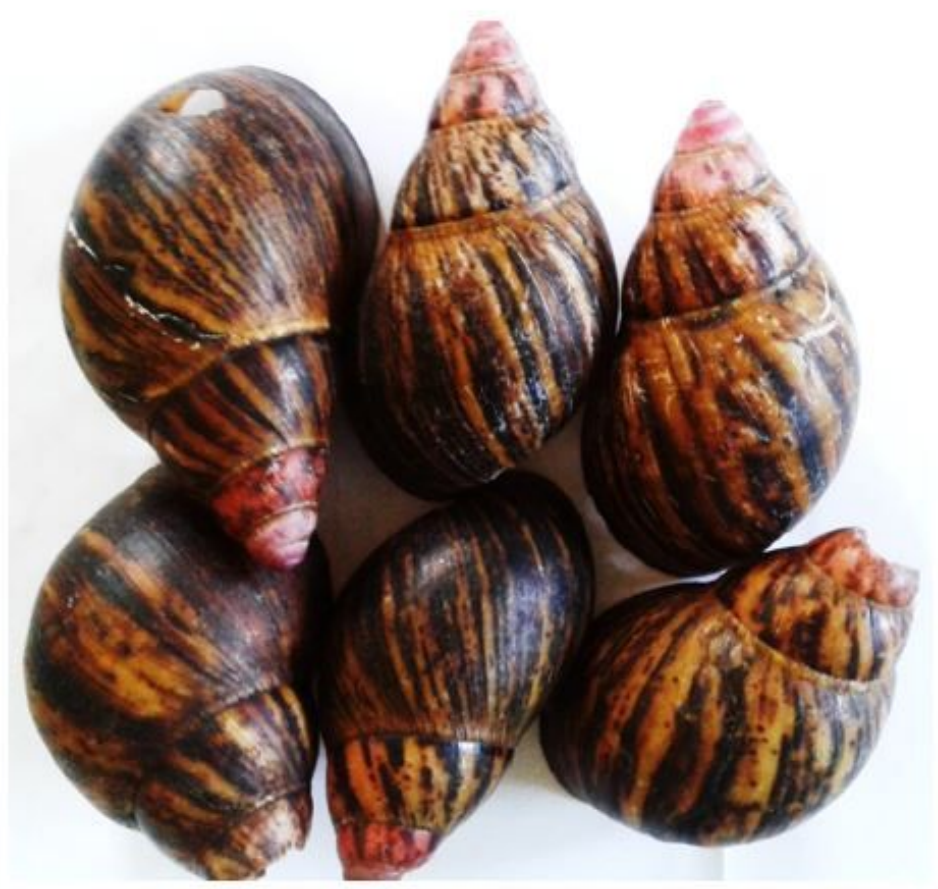

(a)

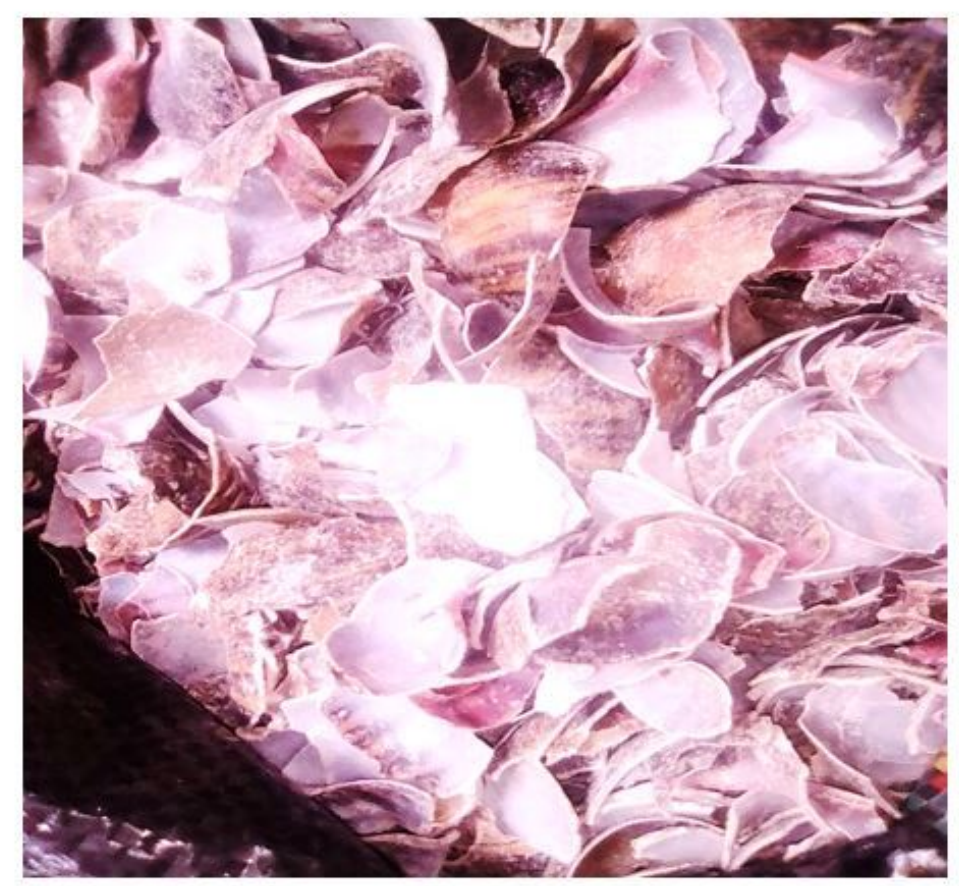

(b)

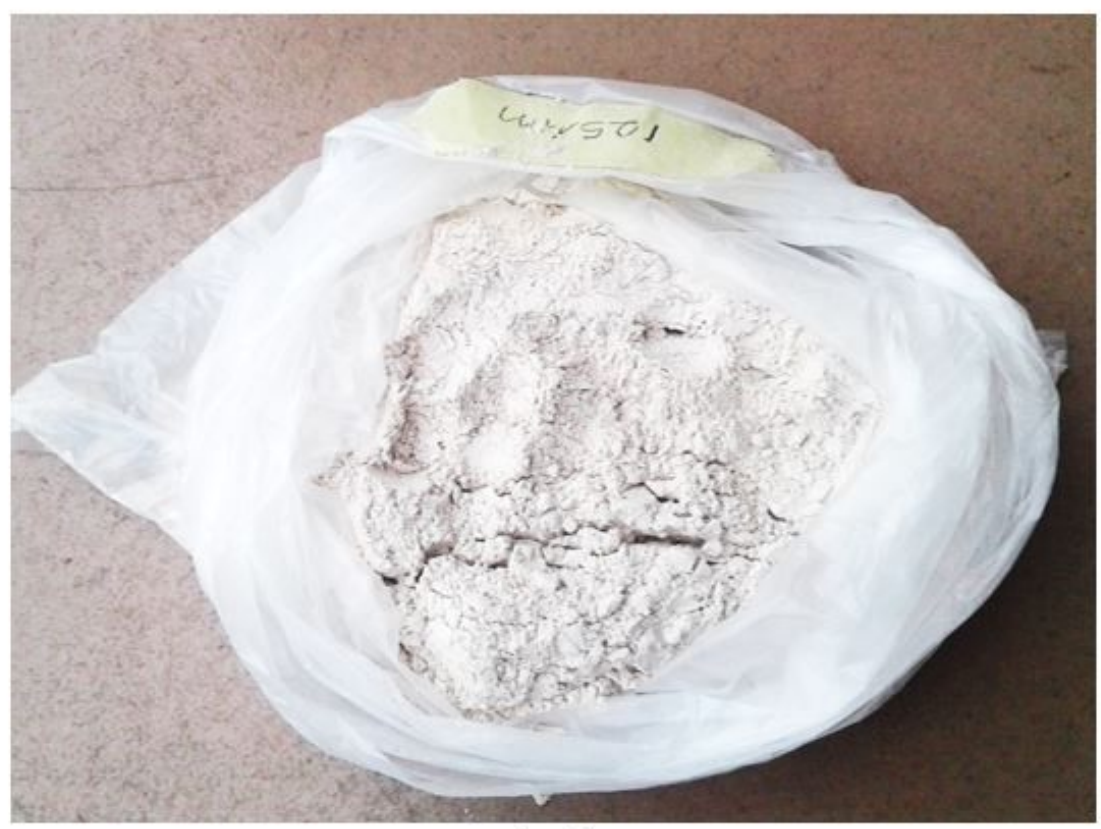

(c)

\section{Figure 1}

Waste shells of African Giant Snail in (a) gathered, (b) crushed, (c) grinded conditions 


\section{Gathering}

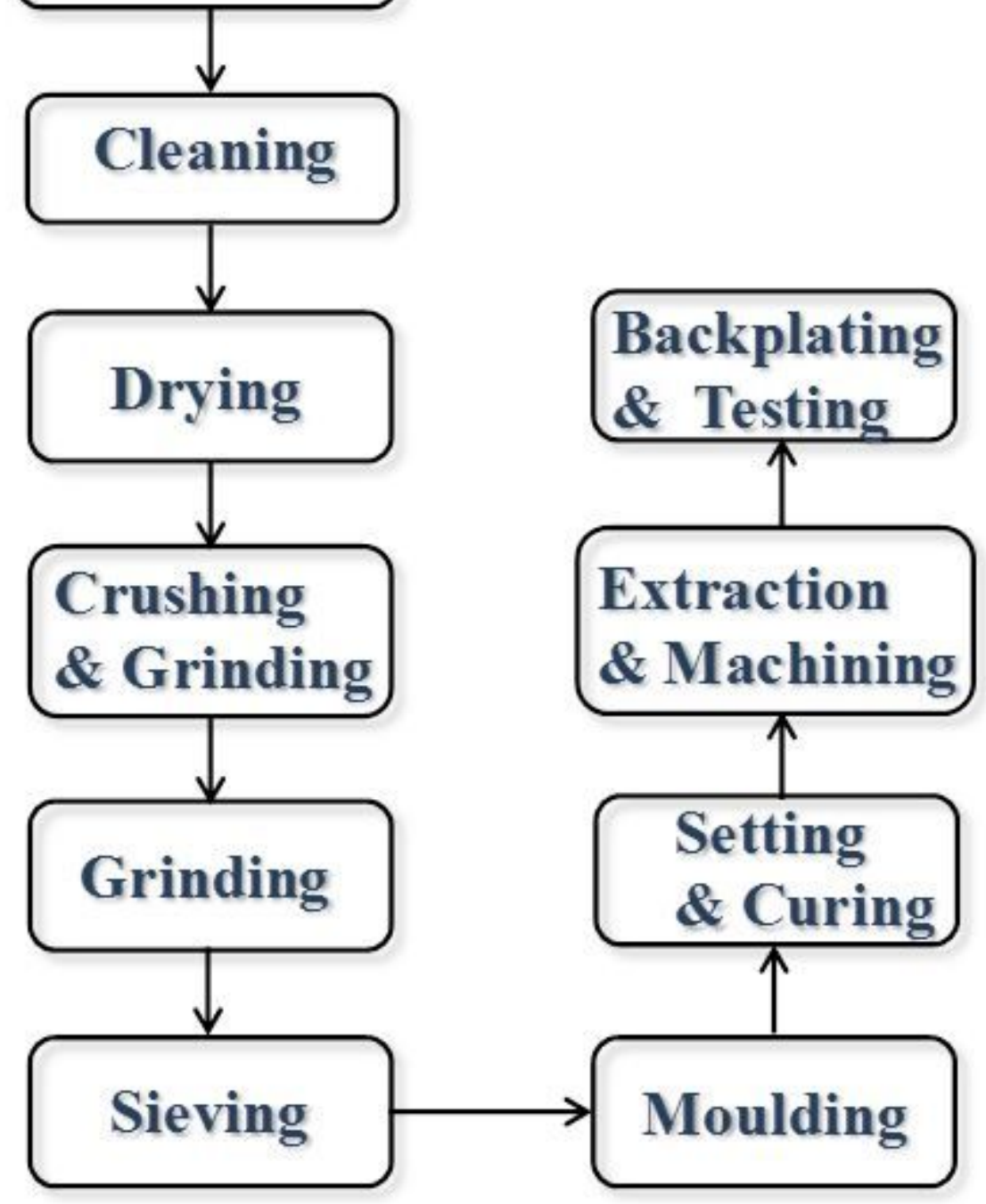

Figure 2

SS-based brake pad sample development process (Ossia et al., [3]) 


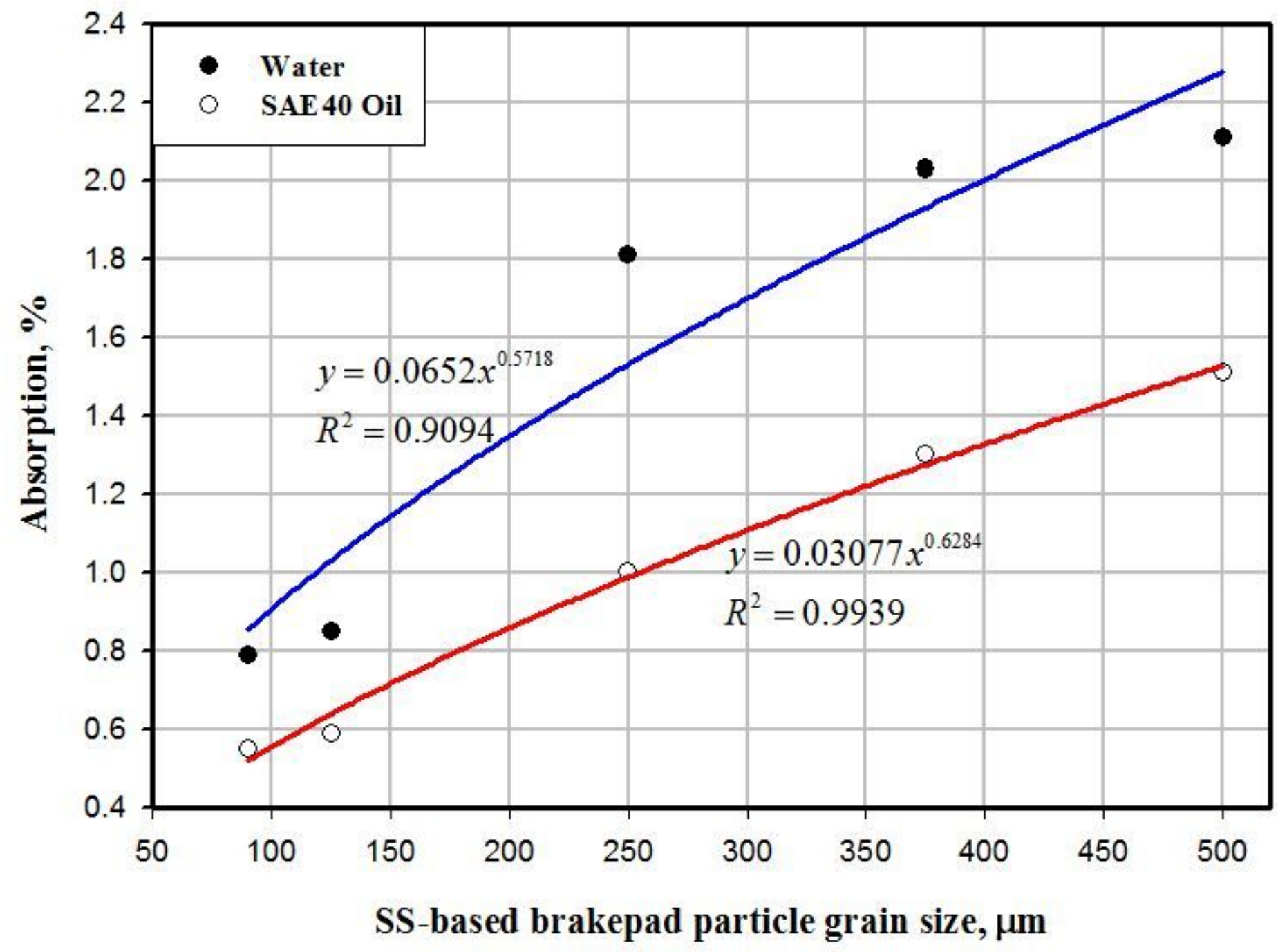

Figure 3

SS-based brake pad sample development process (Ossia et al., [3]) 


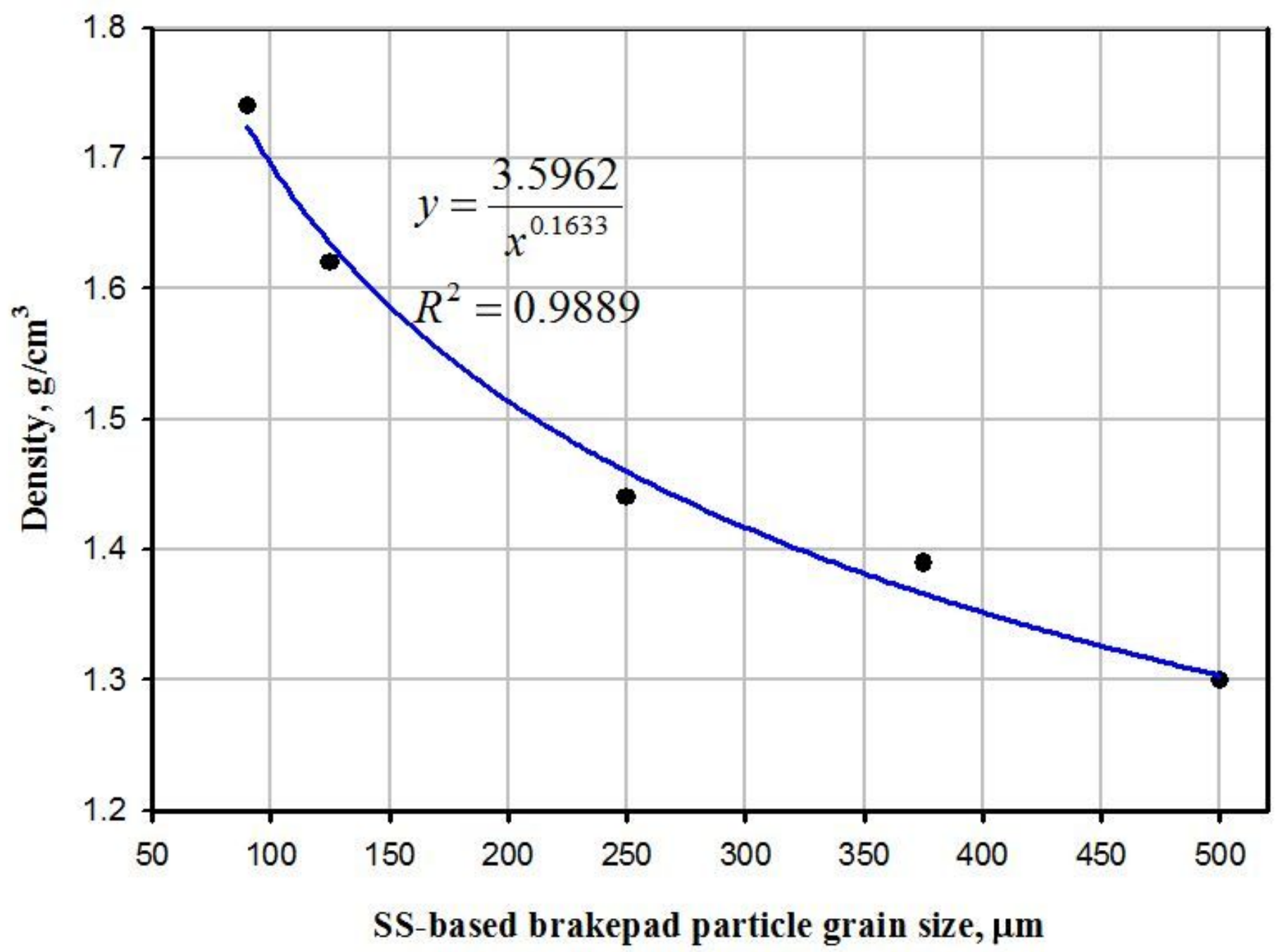

Figure 4

Density of SS-based brake pad for different particle grain sizes 


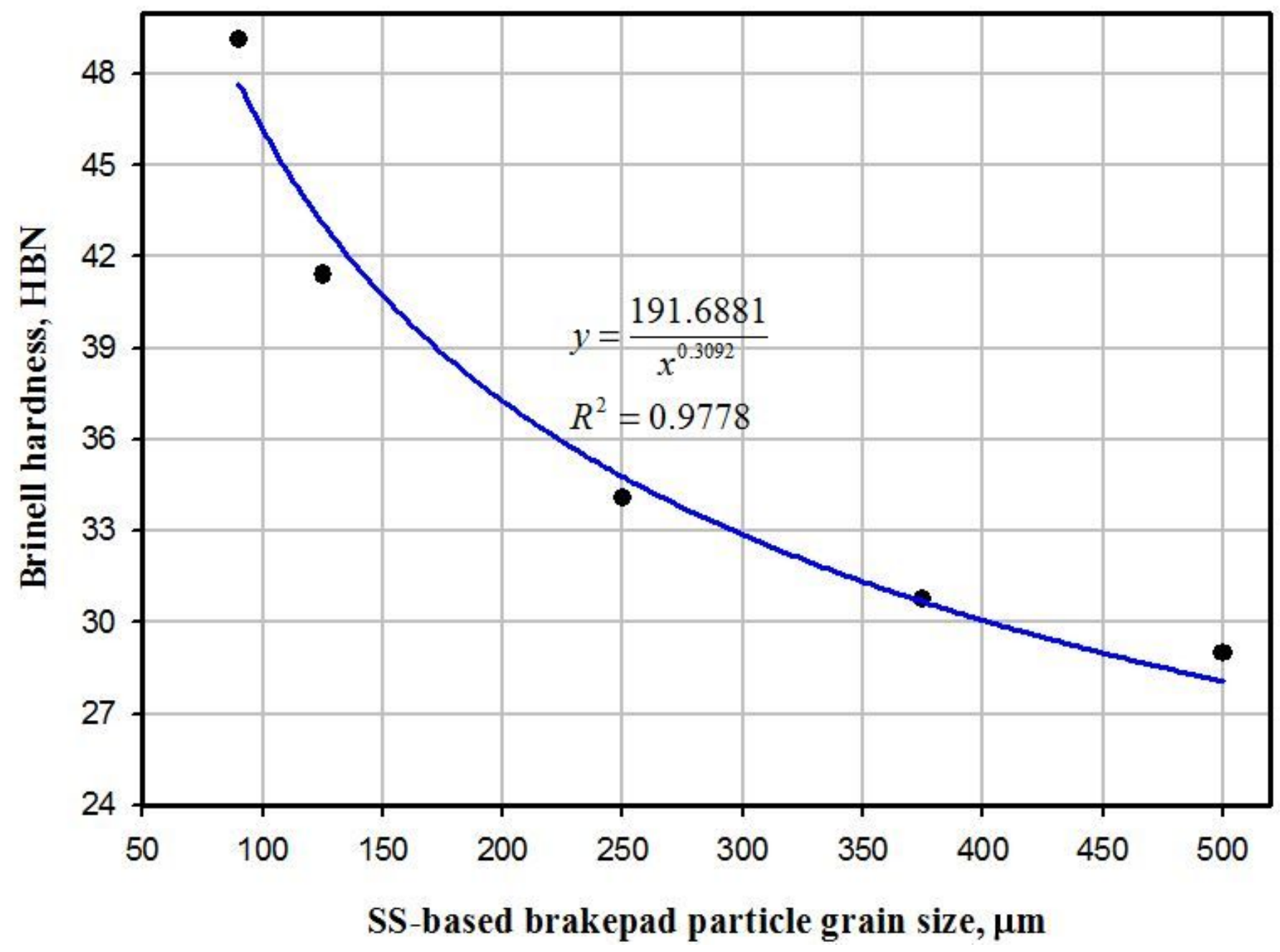

Figure 5

Hardness of experimental brake pads compared with commercial brake pad 


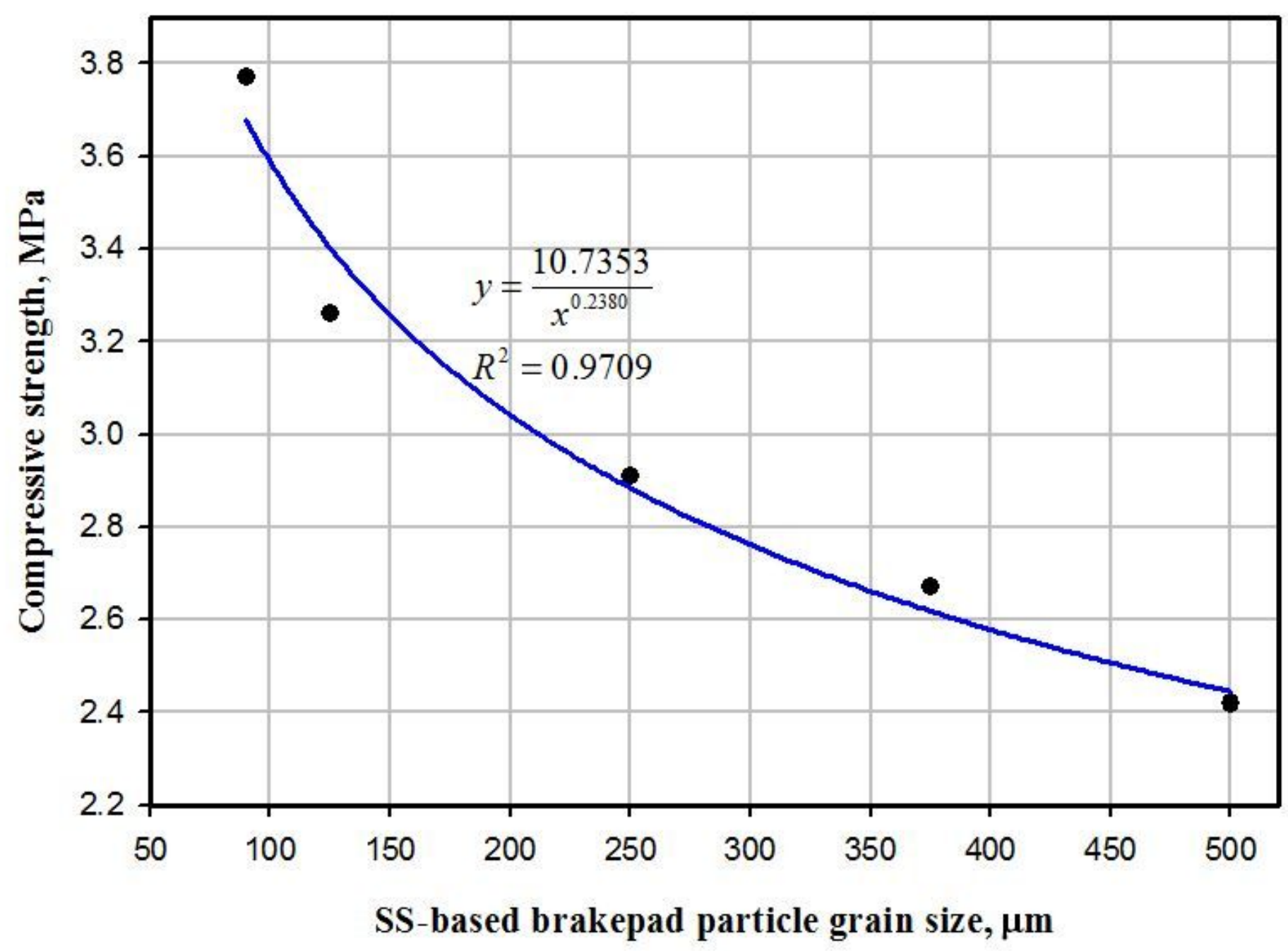

Figure 6

Compressive Strength of the SS-based brake pads with different particle grain sizes 


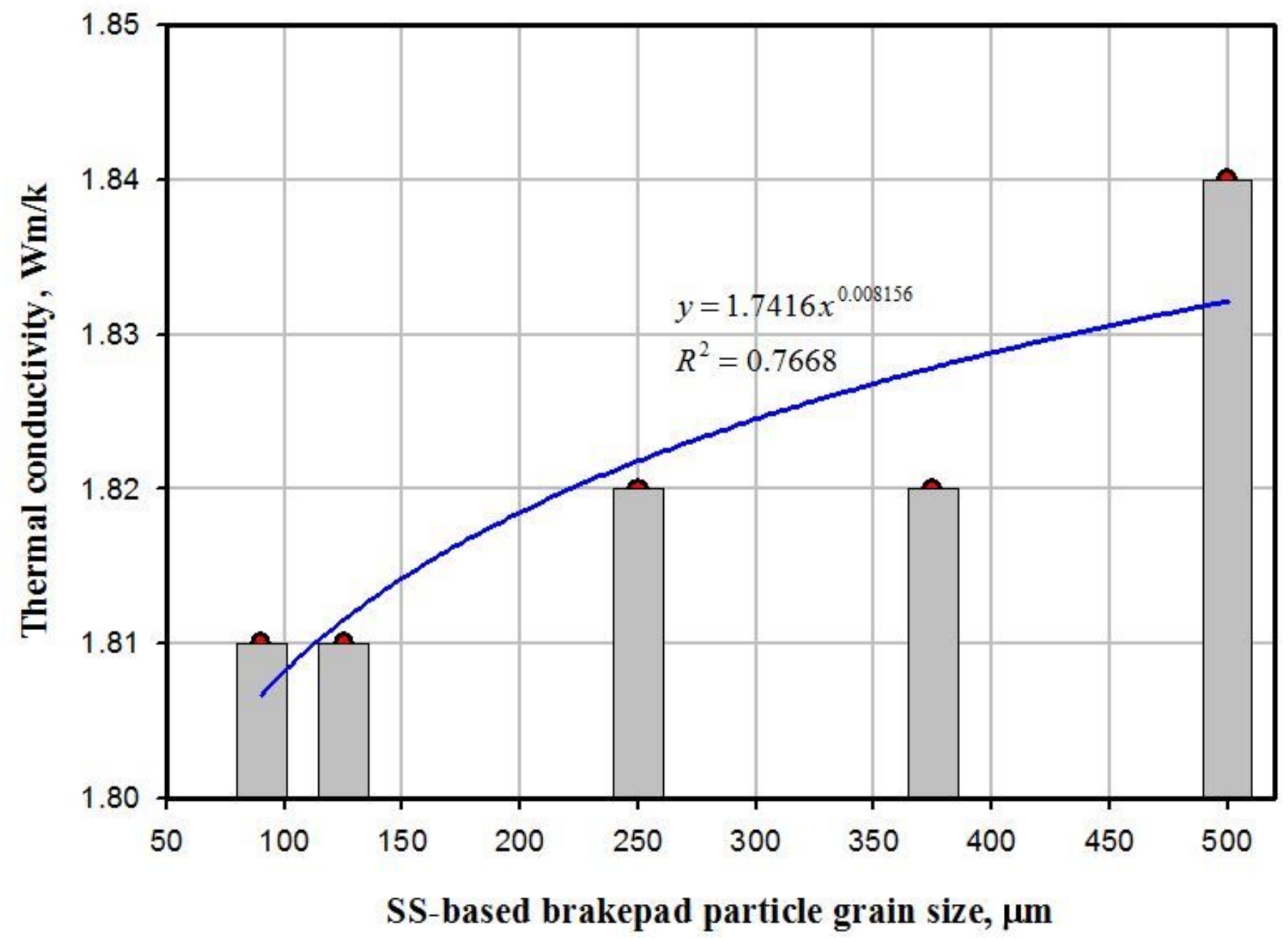

Figure 7

Thermal conductivity of SS-based brakepads with different particle grain sizes 
Start: -0.037 min: -0.037 max: 0.669 mean: 0.617 std. dev. $: 0.078$

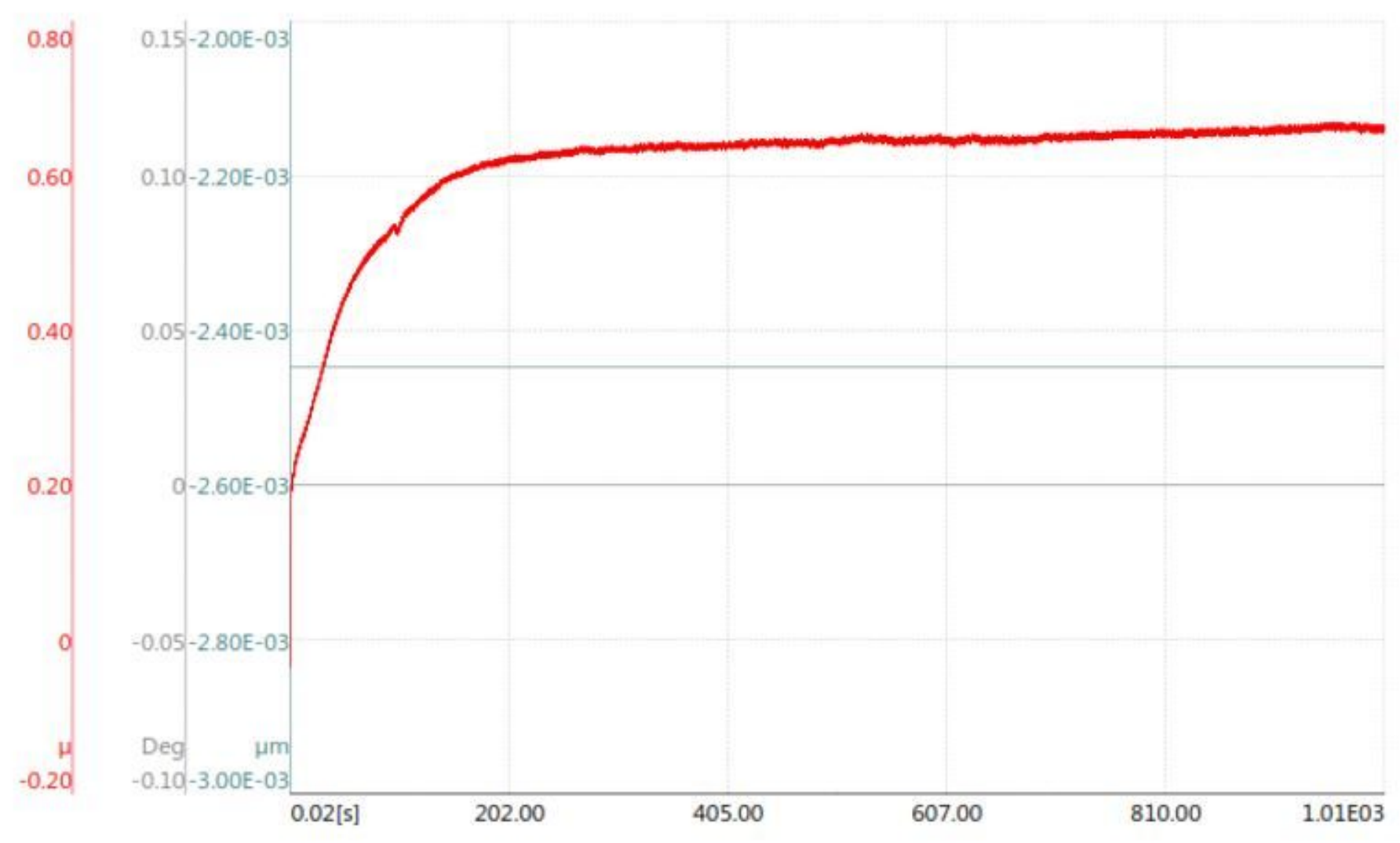

Figure 8

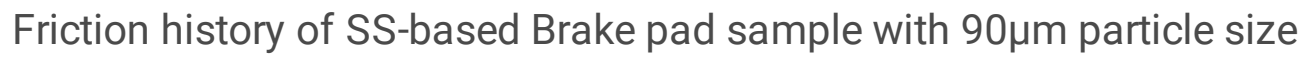




Start: $0.044 \min : 0.044 \max : 0.669$ mean : 0.495 std. dev. 0.178

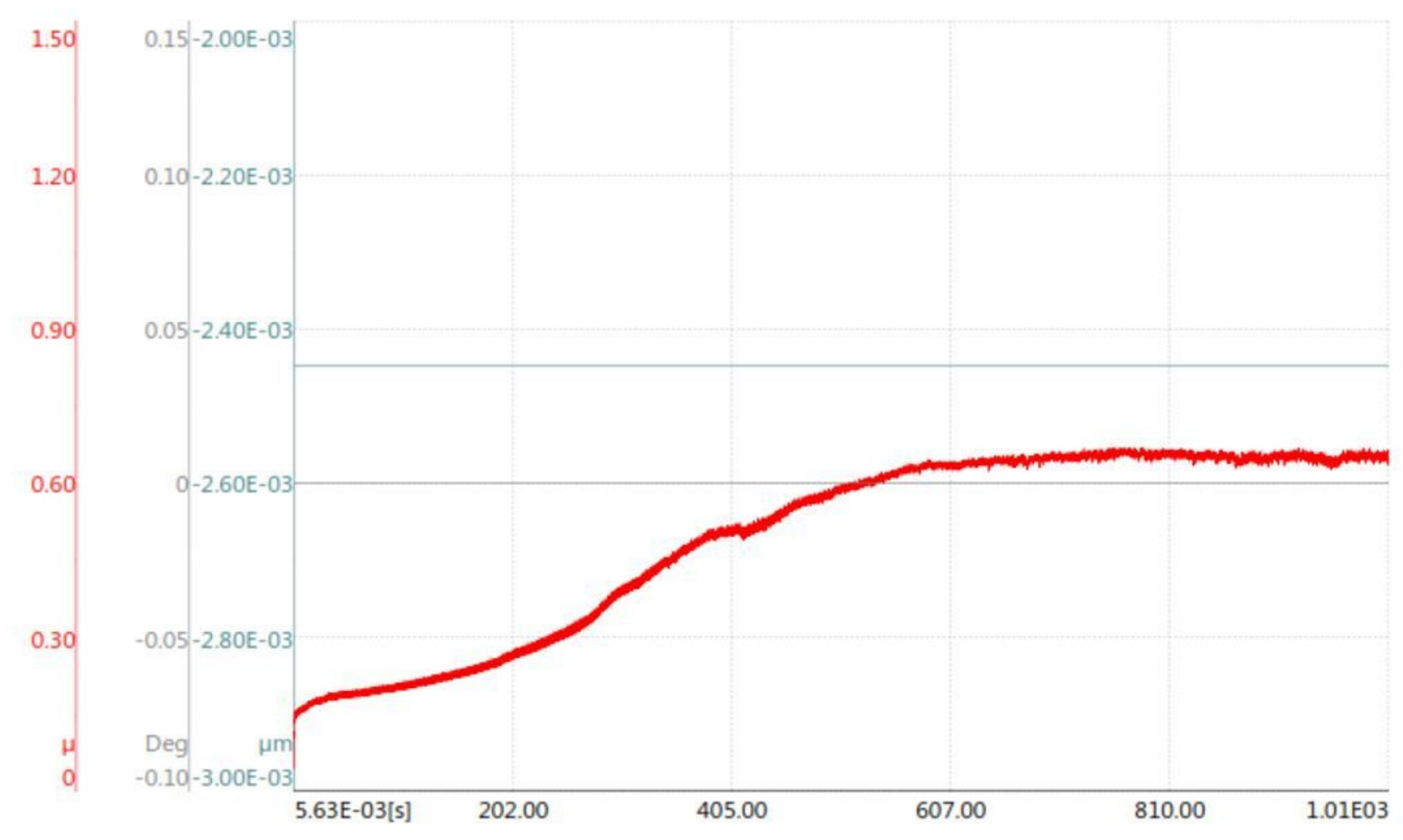

Figure 9

Friction history of SS-based Brake pad sample with $125 \mu \mathrm{m}$ particle size 


Start: $0.034 \min : 0.034 \max : 0.389$ mean : 0.342 std. dev. : 0.036

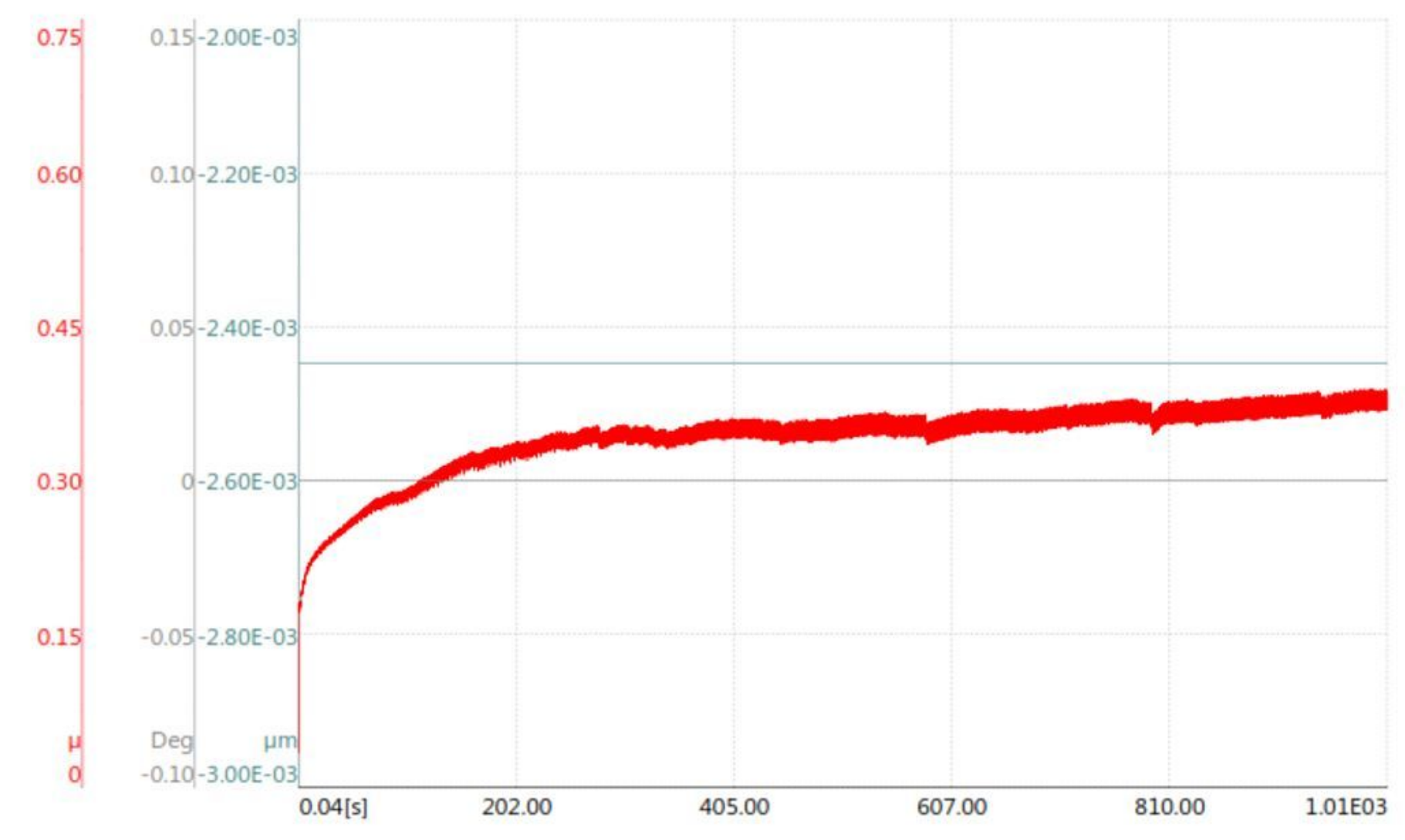

Figure 10

Friction history of SS-based Brake pad sample with $250 \mu \mathrm{m}$ particle size 


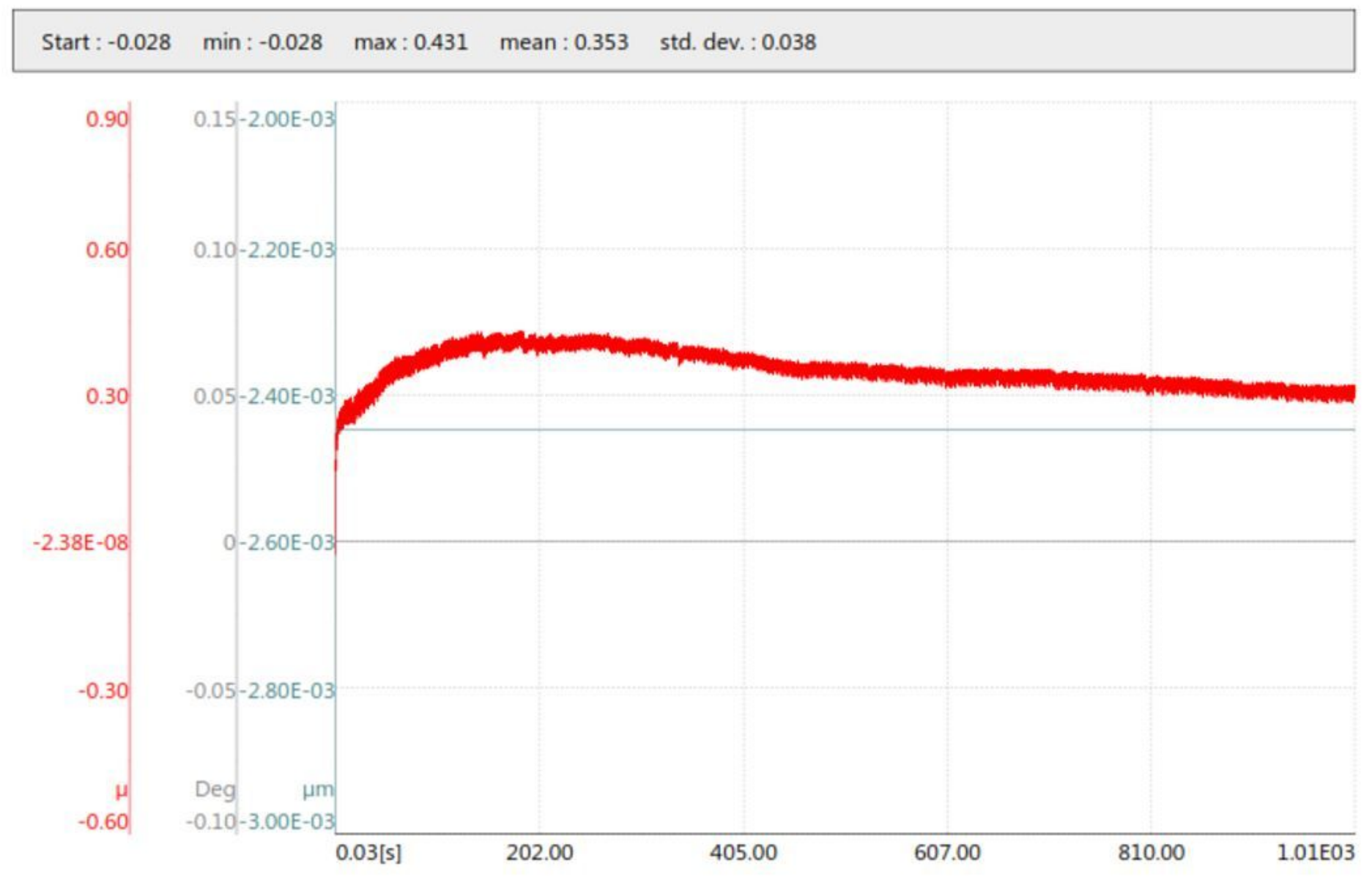

\section{Figure 11}

Friction history of SS-based Brake pad sample with $375 \mu \mathrm{m}$ particle size 


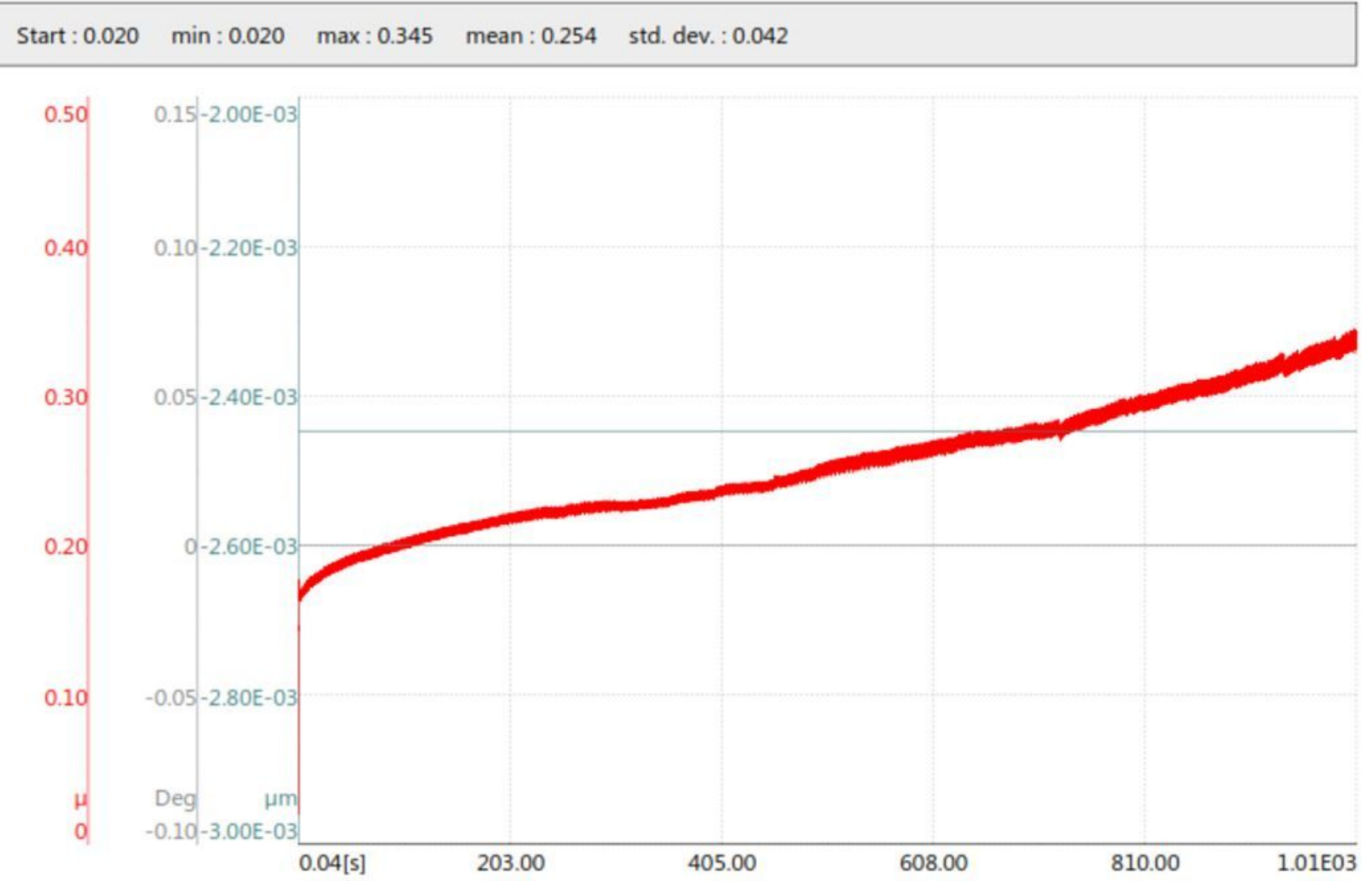

Figure 12

Friction history of SS-based Brake pad sample with $500 \mu \mathrm{m}$ particle size 


\section{Start :0.000 min:0.000 max:0.247 mean:0.223 std. dev. 0.015}

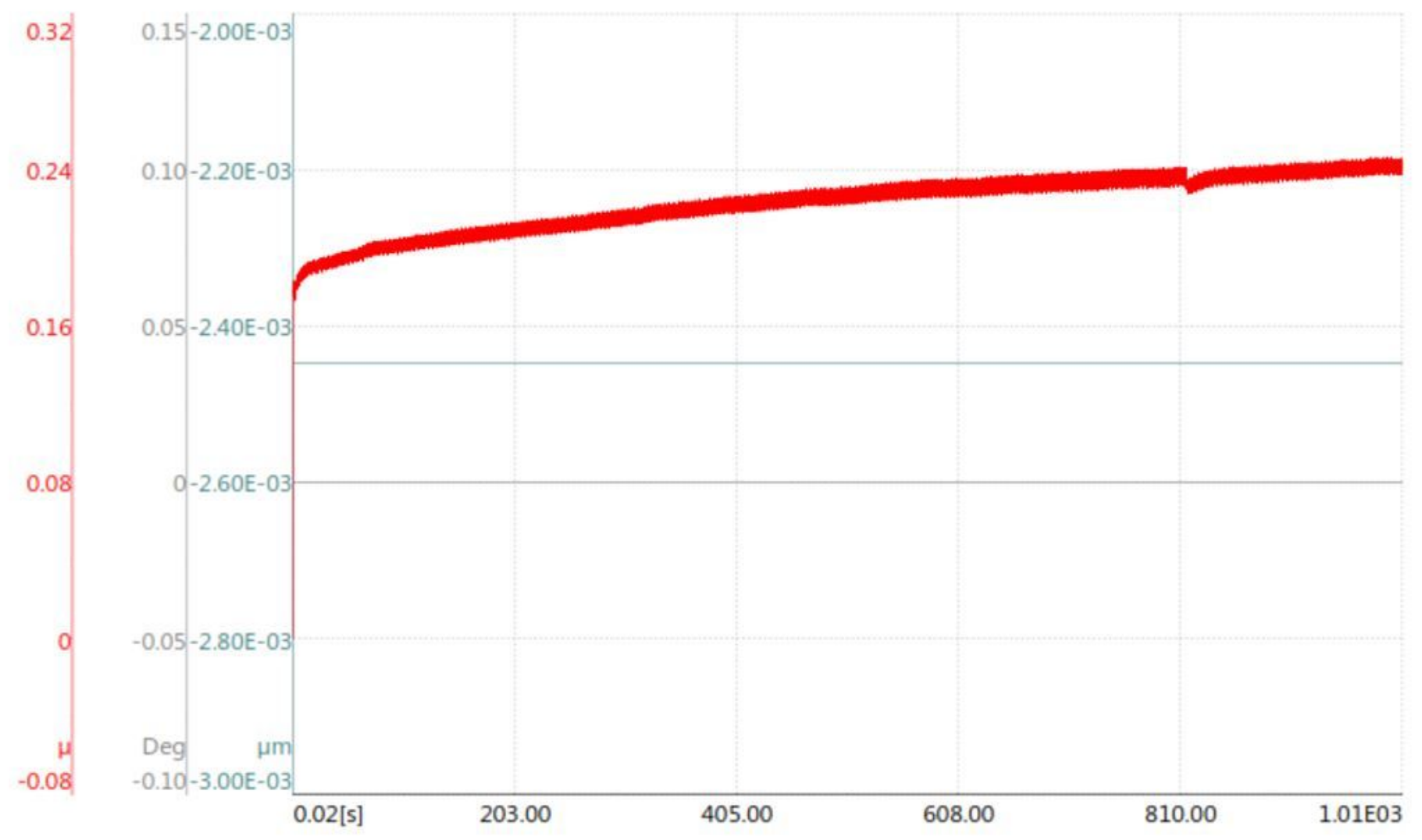

Figure 13

Friction history of the control brake pad sample 


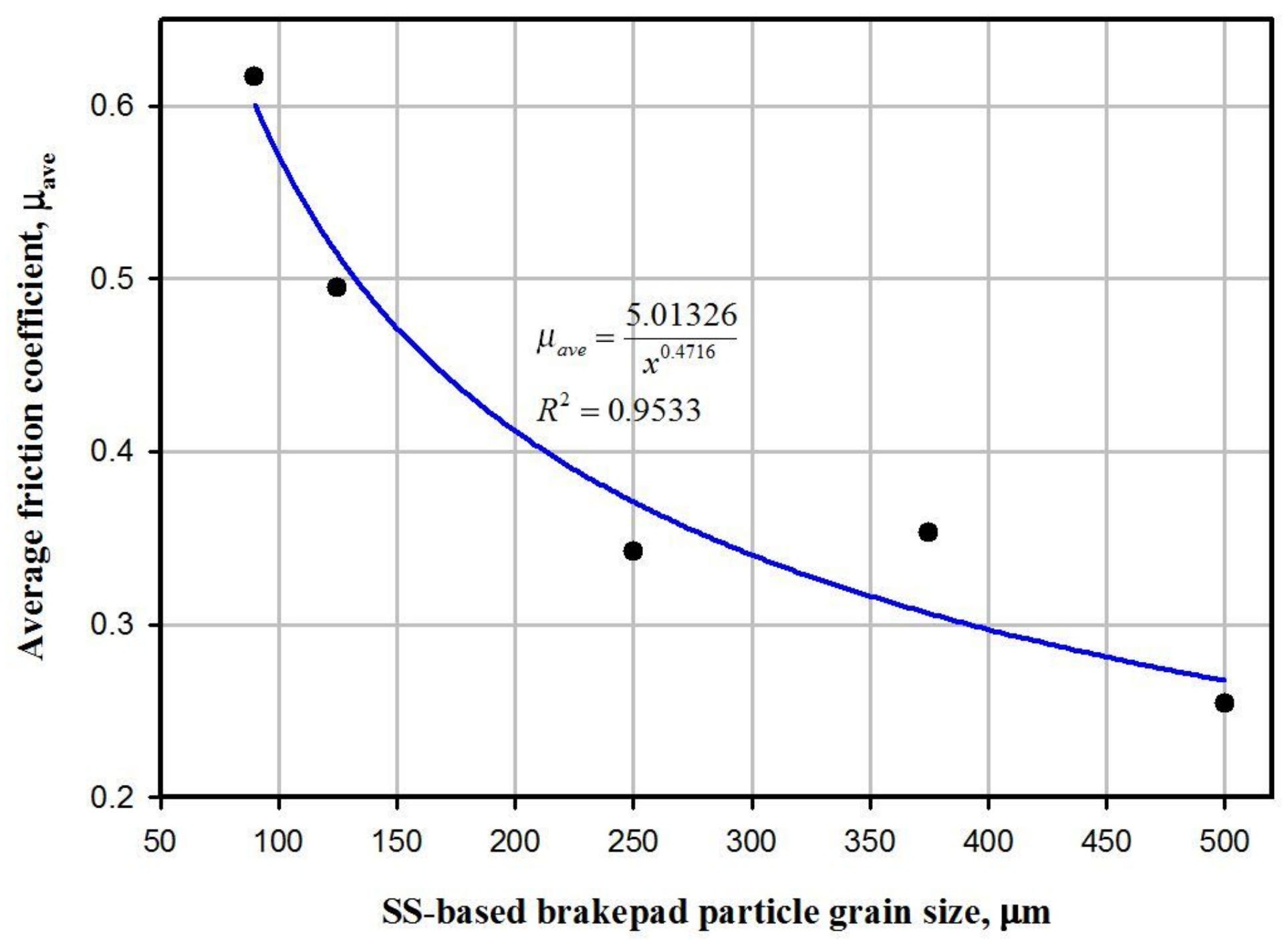

Figure 14

Average friction coefficient of SS-based brake pad samples with different grain sizes Where coefficient of determination R2 $=0.9533$, standard error of estimate $=0.0358$, and $p$-value $=0.0043$. It is obvious that as the particle size increases, the average friction coefficient decreases, hence corroborating Amaren et al [5] negative effect. 


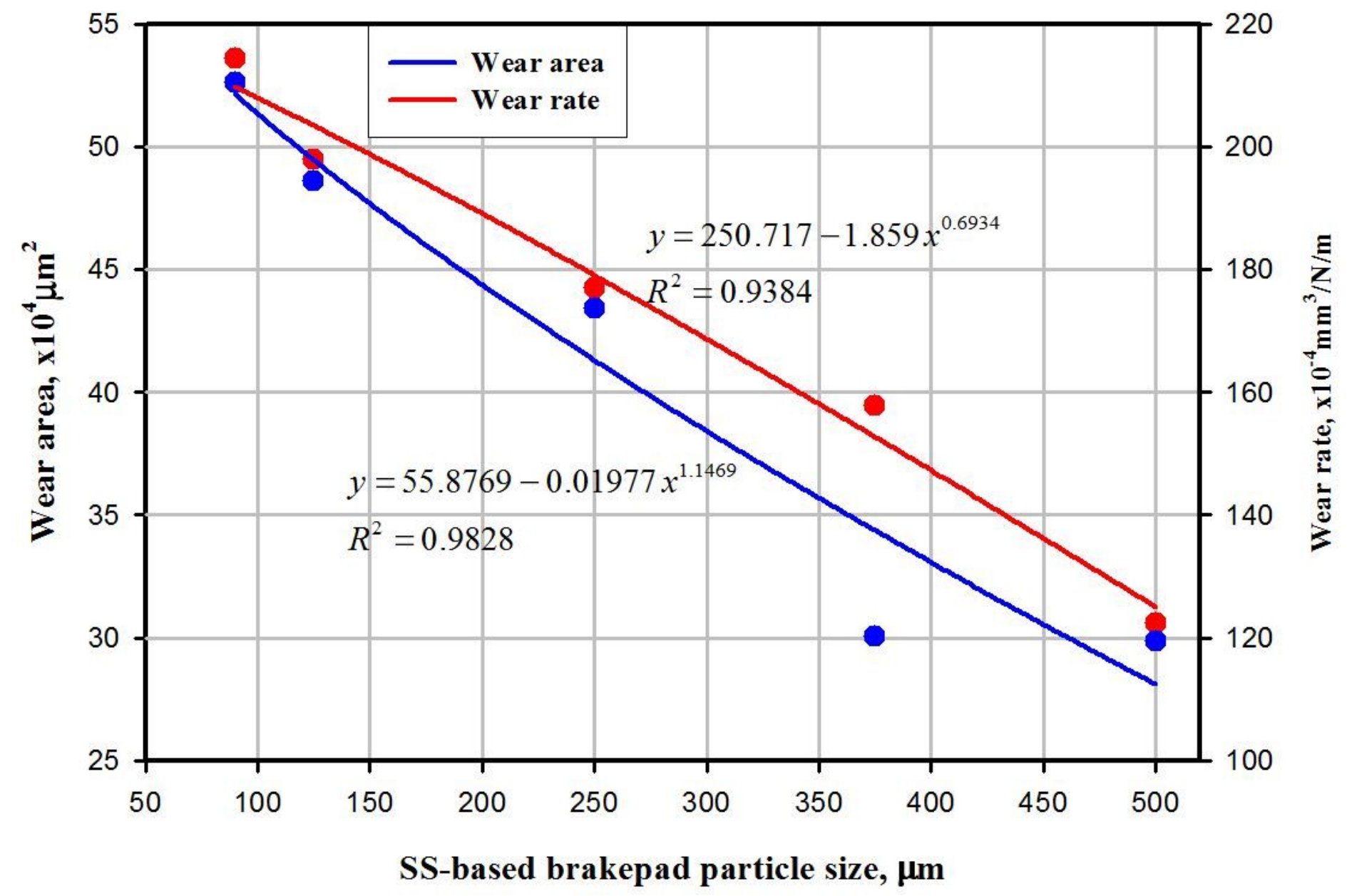

Figure 15

Wear characterization of SS-based brake pads with different particle grain sizes 


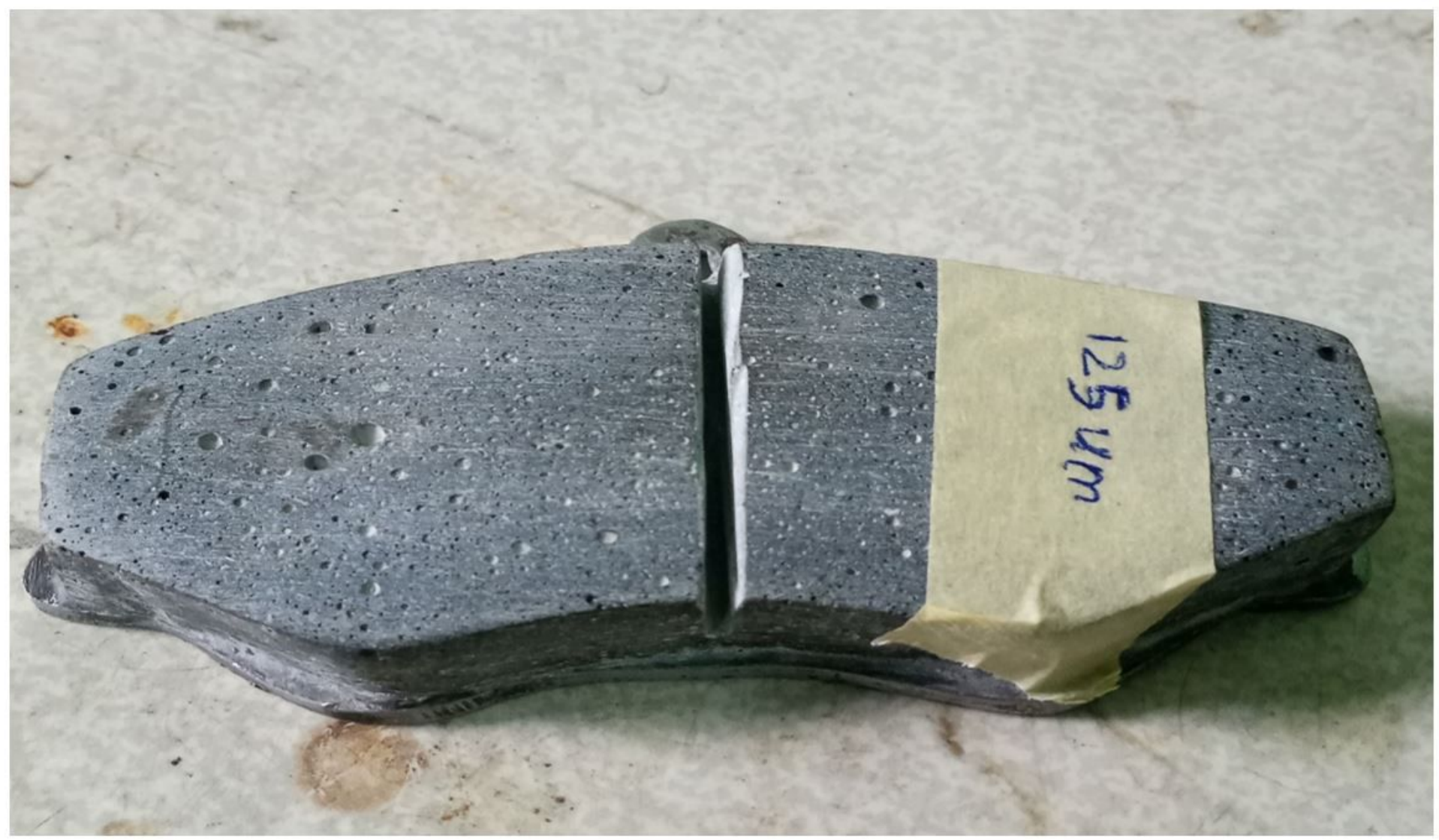

Figure 16

The finished SS-brake pad with $125 \mu \mathrm{m}$ particle grain size 